\title{
Autoignition of Gasoline Surrogates at Low Temperature Combustion Conditions
}

\author{
Goutham Kukkadapu ${ }^{1}$, Kamal Kumar ${ }^{1}$, Chih-Jen Sung ${ }^{1}$, Marco Mehl ${ }^{2}$, and William J. Pitz ${ }^{2}$ \\ ${ }^{1}$ Department of Mechanical Engineering, University of Connecticut, Storrs, CT 06269 \\ ${ }^{2}$ Lawrence Livermore National Laboratory, Livermore, CA 94551
}
Keywords: Research Grade Gasoline, Gasoline Surrogates, Autoignition, Rapid Compression Machine, Ignition delays, Low Temperature Combustion

\author{
Corresponding Author: \\ Chih-Jen Sung \\ Department of Mechanical Engineering \\ University of Connecticut \\ Room 484, United Technologies Engineering Building \\ Storrs, CT 06269, USA \\ Phone: (860) 486-3679 \\ Fax: (860) 486-5088 \\ Email: cjsung@engr.uconn.edu
}

Submitted for publication in Combustion and Flame

Accepted: January 26, 2015

Manuscript Reference Number: CNF-D-14-00522R1 


\title{
Autoignition of Gasoline Surrogates at Low Temperature Combustion Conditions
}

\author{
Goutham Kukkadapu ${ }^{1}$, Kamal Kumar ${ }^{1}$, Chih-Jen Sung ${ }^{1}$, Marco Mehl ${ }^{2}$, and William J. Pitz ${ }^{2}$ \\ ${ }^{1}$ Department of Mechanical Engineering, University of Connecticut, Storrs, CT 06269 \\ ${ }^{2}$ Lawrence Livermore National Laboratory, Livermore, CA 94551
}

\begin{abstract}
Understanding the autoignition characteristics of gasoline is essential for the development and design of advanced combustion engines based on low temperature combustion (LTC) technology. Formulation of an appropriate gasoline surrogate and advances in its comprehensive chemical kinetic model are required to model autoignition of gasoline under LTC conditions. Ignition delays of two surrogates proposed in literature for a research grade gasoline (RD387), including a three-component mixture of $i s o$-octane, $n$-heptane, and toluene and a four-component mixture with the addition of an olefin (2-pentene), were measured in this study using a rapid compression machine (RCM). The present RCM experiments focused on two fuel lean conditions in air corresponding to equivalence ratios of $\phi=0.3$ and 0.5 , at two compressed pressures of $P_{C}=20$ bar and 40 bar in the compressed temperature range of $T_{C}=665-950 \mathrm{~K}$. Comparison of the measured ignition delays of two gasoline surrogates with those of RD387 reported in our previous study shows that the four-component surrogate performs better in emulating the autoignition characteristics of RD387. In addition, numerical simulations were carried out to assess the comprehensiveness of the corresponding gasoline surrogate model from Lawrence Livermore National Laboratory. The performance of the chemical kinetic model was noted to be pressure dependent, and the agreement between the experimental and simulated results was found to depend on the operating conditions. A good agreement was observed at a compressed pressure of 20 bar, while a reduced reactivity was predicted by the chemical kinetic model at 40 bar. Brute force sensitivity analysis was also conducted at varying pressures, temperatures, and equivalence ratios to identify the reactions that influence simulated ignition delay times. Finally, further studies for improving the surrogate kinetic model were discussed and suggested.
\end{abstract}




\section{Introduction}

Internal combustion engines (ICEs) are expected to power light-duty transportation vehicles over the coming decades [1] despite the emergence of other energy conversion technologies. Therefore, advanced ICEs capable of operating at both high efficiencies and low emission levels need to be developed to overcome the prevailing challenges of depletion of fossil fuel reserves and detrimental effects of combustion generated emissions. Low temperature combustion (LTC) technology is one novel approach that operates with extremely lean fuel/air or highly diluted mixtures and under high compression ratios resulting in high efficiency and low emissions [1]. Homogeneous charge compression ignition (HCCI), reactivity controlled compression ignition (RCCI), and premixed charge compression ignition (PCCI) engines are some variants of LTC. Since LTC relies heavily on autoignition kinetics of the fuels, it is imperative to develop high fidelity chemical kinetic models to simulate the autoignition process over a wide range of operating conditions. As gasoline is the major transportation fuel for light-duty vehicles, this study focuses on gasoline autoignition kinetics.

The modeling of gasoline chemical kinetics is complicated by the compositional complexity of the real fuel which typically consists of hundreds of hydrocarbons. Developing a chemical kinetic model describing autoignition of all the gasoline components is currently not feasible; therefore simpler surrogates with a limited number of hydrocarbons are commonly used to replicate the autoignition kinetics of real gasoline. A comprehensive chemical kinetic model for a real fuel requires the identification of an appropriate surrogate and the development of a chemical kinetic model to describe the combustion kinetics of the surrogate. Pitz et al. [2] reviewed and identified the targets for the formulation of gasoline surrogates, and recommended the hydrocarbon candidates for surrogate formulation. Considering the relevance of flame 
propagation, knocking, and ignition phasing to advanced ICEs, a surrogate should be formulated to match $\mathrm{H} / \mathrm{C}$ ratio, octane rating, and crank angle degrees corresponding to $10 \%$ and $50 \%$ of the total heat release (denoted as CA 10 and CA 50, respectively) of the target gasoline [2]. Regarding the octane rating, it is also essential to match Research Octane Number (RON), Motor Octane Number (MON), and Sensitivity (S) of the surrogate to those of the target gasoline. In addition, Pitz et al. [2] pointed out the needs for fundamental experimental data from flow reactors, shock tubes, rapid compression machines, laminar flames, and jet stirred reactors, at varying pressures, temperatures, and equivalence ratios.

In terms of gasoline surrogate components, $n$-heptane, iso-octane, toluene, cyclohexane, methyl-cyclohexane $(\mathrm{MCH})$, 1-pentene, 2-pentene, di-isobutylene, ethanol, etc. have been identified as candidates for surrogate constituents. Several surrogate mixtures have been formulated to emulate the combustion characteristics of gasoline fuels. Although the Primary Reference Fuels (PRF's), mixtures of iso-octane and $n$-heptane, have been widely used to understand ignition of gasoline in spark ignition engines, they are not able to meet some targets, specifically the H/C ratio and Sensitivity, highlighting the need for a more complex surrogate formulation. This led to the use of ternary surrogate mixtures, such as Toluene Reference Fuels (TRF's), which are mixtures of iso-octane, $n$-heptane, and toluene [3,4], and blends of isooctane, toluene, and 1-hexene [5]. Additionally, a four-component mixture consisting of TRF and 2-pentene was proposed by Mehl et al. [6] as a gasoline surrogate, while Naik et al. [7] suggested a five-component surrogate consisting of $n$-heptane, iso-octane, toluene, $\mathrm{MCH}$, and 1pentene. Furthermore, investigations have been conducted to understand the kinetic interactions between the constituents of these surrogates [e.g., 5,8,9]. 
While fundamental investigations on fully-blended gasoline fuels are essential for validation and formulation of their surrogates, there were only a limited number of studies reported in the literature. Using a shock tube, Gauthier et al. [4] measured ignition delays of a full blend nonoxygenated, research grade gasoline (RD387) at varying equivalence ratios of $\phi=0.5,1.0$, and 2.0 covering two pressures ranges of $15-25$ atm and $45-60$ atm in the high temperature range of 850-1280 K. A recent study on RD387 by Kukkadapu et al. [10] conducted autoignition delay measurements in a rapid compression machine (RCM) at varying equivalence ratios $(\phi=0.3,0.5$, and 1.0) and compressed pressures $\left(P_{C}=20\right.$ and 40 bar $)$, in the low-to-intermediate temperature range of 640-955 K. Sjöberg et al. [11] and Dec et al. [12] have used RD387 for their engine experiments, showing different heat release characteristics at different operating conditions and temperature ranges. In addition, laminar flame speeds of gasoline fuels were reported by Jerzembeck and Peters [13] and Tian et al. [14]. Recently, Sarathy et al. [15] studied ignition characteristics of two gasoline blends and a PRF mixture which exhibited identical ASTM octane ratings. These experimental studies on gasoline fuels $[4,10-15]$ have provided validation datasets for the formulation of gasoline surrogates and the development of surrogate models over different combustion modes.

The shock tube study of Gauthier et al. [4] also found that the ignition delays of a TRF mixture comprising 63\% iso-octane / 17\% $n$-heptane / 20\% toluene (all by liquid volume) compared well with those of RD387 at high-temperature conditions investigated therein. This TRF surrogate proposed by Gauthier et al. [4] is hereafter referred to as Stanford A surrogate. As mentioned earlier, Mehl et al. [6], led by Lawrence Livermore National Laboratory (LLNL), formulated a quaternary gasoline surrogate, consisting of 57\% iso-octane / 16\% n-heptane / $23 \%$ toluene / 4\% 2-pentene (by liquid volume), using a surrogate formulation methodology based on 
a chemical kinetic model. This four-component surrogate is denoted as LLNL surrogate in the following. In addition, the surrogate model of Mehl et al. [6] was shown to emulate the shock tube ignition delays, laminar flame speeds, and engine data of gasoline fuels available in the literature with a good level of agreement. In view of the importance of the low-to-intermediate temperature chemistry in advanced engines operating at LTC conditions, Kukkadapu et al. [16] measured the ignition delays of two gasoline surrogates, namely Stanford A and LLNL, in an RCM for stoichiometric fuel/air mixtures at compressed pressures of $P_{C}=20$ and $40 \mathrm{bar}$.

Table 1 shows that both the Stanford A and the LLNL surrogates match closely with the key properties of the target RD387 gasoline. A detailed discussion on the selection of these two gasoline surrogates can be found in [16]. By comparing the ignition delays of the two surrogates with those of RD387 from [10], it was demonstrated in [16] that the four-component LLNL surrogate better matches the RCM ignition characteristics of gasoline than the three-component Stanford A surrogate. It was further observed in [16] that though the simulated ignition delays using the chemical kinetic model of the LLNL surrogate [6,17] compared well with the experimental data of gasoline, the comparison of the measured and simulated ignition delays of two surrogates did not exhibit similar level of agreement. Furthermore, based on the comparison of surrogate experiments and modeling results, a significant difference in reactivity was observed especially at conditions of low temperature and high pressure [16].

The objective of the current study is to extend the work of Kukkadapu et al. [16] by investigating the autoignition characteristics of the Stanford A and the LLNL surrogates under LTC-relevant conditions, i.e. elevated pressures (10-75 bar), low-to-intermediate temperatures (600-1100 K), and fuel lean equivalence ratios, in an RCM. Understanding the performance of gasoline surrogates and their model at these off-stoichiometric conditions with respect to 
gasoline autoignition is vital for the development of next-generation advanced-combustion engines. In addition, direct comparisons of the experimental ignition delays using surrogates with those predicted by the corresponding chemical kinetic model will help assess the fidelity of the surrogate model $[6,17]$, as well as provide insights into the model refinement. Therefore, the current study aim to close the gap under fuel lean and high pressure conditions, by experimentally comparing the ignition delay responses of the two surrogates with those of RD387 from [10] and computationally validating the predictability and comprehensiveness of the chemical kinetic model of Mehl et al. $[6,17]$.

\section{Experimental Specifications}

A heated rapid compression machine has been used for the present experiments. A creviced piston, as designed and optimized in Mittal and Sung [18], is pneumatically driven during the compression stroke. The piston is brought to rest towards the end of compression by a hydraulic pin-groove mechanism. Compression is a single stroke event in this RCM and compression ratio can be varied between 7 and 17 by changing the stroke and clearance lengths. The compression event typically occurs in 25-35 ms. Dynamic pressure in the reaction cylinder was measured using a Kistler 6125B thermal shock-resistant transducer in conjunction with a Kistler 5010B charge amplifier. Further details of the current RCM can be found in Mittal and Sung [18].

Homogeneous fuel/oxidizer mixtures were prepared in a stainless steel mixing chamber equipped with a magnetic stirrer and heaters capable of heating the entire system up to $420 \mathrm{~K}$. The magnetic stirrer at the bottom of the mixing chamber helps in the preparation of homogeneous mixtures. Fuels were injected into the mixing chamber on a gravimetric measure with help of syringes. The mass of fuel injected into the mixing chamber was measured using an 
electronic weighing balance which has a resolution of 0.01 gram. High purity iso-octane (99.8\%), $n$-heptane (>99\%), toluene (>99.9\%), and 2-pentene (99\%) supplied by Sigma-Aldrich were used for the current experiments. We note that 2-pentene used in the current experiments is a mixture of its $70 \%$ trans- and $30 \%$ cis- isomers. Moreover, ultra-high purity oxygen and nitrogen (both 99.99\%) supplied by Airgas were used for preparation of premixed charges and were filled in the mixing chamber on a manometric measure.

The RCM reaction chamber, the mixing chamber, and the intake manifolds were heated to the set pre-heat temperature for about $2 \frac{1}{2}-3$ hours before the experiments were conducted. Compressed pressure $\left(P_{C}\right)$ and compressed temperature $\left(T_{C}\right)$ can be varied independently by varying the compression ratio, intake charge pressure $\left(P_{0}\right)$, and/or intake temperature $\left(T_{0}\right)$. The compressed temperature can then be deduced from the adiabatic core hypothesis,

$$
\int_{T_{0}}^{T_{c}} \frac{\gamma}{\gamma-1} \frac{\mathrm{d} T}{T}=\ln \left(\frac{P_{c}}{P_{0}}\right),
$$

where $\gamma$ is the ratio of the specific heats and is temperature dependent. The thermodynamic database taken from Mehl et al. [6,17] was used for the determination of the compressed temperatures of the two surrogates in RCM experiments. Based on Eq. (1), the uncertainty in determining compressed temperature arises due to the uncertainties in the measurements of $P_{0}$, $T_{0}$, and $P_{C}$, and was estimated to be about $\pm 5 \mathrm{~K}$. In the present experimental setup, the major contribution to the $T_{C}$ uncertainty was from the uncertainty of $T_{0}$ measurements, which was about $\pm 1.5 \mathrm{~K}$ for the thermocouple employed.

Table 2 lists the pre-heat temperatures (i.e. intake temperatures) used in the current study along with the $T_{0}$ values investigated in our earlier studies $[10,16]$. The present investigation was conducted at pressures and equivalence ratios identical to our earlier study for RD387 [10] so as to facilitate direct comparison of autoignition delays measured using surrogates and RD387. 
The dynamic pressure history in the reaction chamber was measured at a sampling rate of 50 $\mathrm{kHz}$, and was the raw data obtained from the present experiments. Similar to the compressed temperature, ignition delay was also deduced from the experimental pressure traces. The RCM ignition delays are measured relative to the end of compression (EOC), denoted as $t=0$, which is chosen as the maximum of the pressure trace during compression stroke. Figure 1 shows the definitions of the first stage ignition delay $\left(\tau_{1}\right)$ and the total ignition delay $(\tau)$ used in the current

study, in which the maximum rate of pressure rise in the post-compression pressure record is used to represent the respective onset of ignition.

Figure 2 demonstrates the typical experimental repeatability of the experimental data. A minimum of five consecutive experimental runs were conducted and the pressure trace corresponding to the ignition delay closest to the mean of the five traces was taken as the representative of the data point. The typical scatter in the ignition delays is less than $10 \%$ of the reported value, and is used to determine the error bars when presenting the experimental data in the following figures. To ensure repeatability, ignition delay data obtained from each new fresh mixture was checked with that from an earlier mixture, if available.

\section{Experimental Results}

\subsection{Autoignition Characteristics of Two Surrogates}

Figure 3 shows the Arrhenius plots of ignition delays and some representative experimental pressure traces recorded at various compressed temperatures, for both the LLNL (left panel) and the Stanford A (right panel) surrogates at fuel/air equivalence ratio of $\phi=0.5$ and $P_{C}=20$ bar. The compressed temperatures in Fig. 3 covers the range of $T_{C}=681-950 \mathrm{~K}$, spanning from the low temperature regime (LTR) to the high temperature regime (HTR), including the negative 
temperature coefficient (NTC) regime. At $P_{C}=20$ bar, it is seen from Fig. 3 that the pressure traces exhibited distinct two-stage ignition behavior for $T_{C}$ in the LTR and NTC regimes, while single stage ignition behavior was observed for $T_{C}$ lying in the HTR.

At $P_{C}=40$ bar, the RCM results with $\phi=0.3$ and 0.5 for the two gasoline surrogates are plotted and compared in Fig. 4, covering $T_{C}$ in the low temperature regime of $668-748 \mathrm{~K}$. When $T_{C}$ was increased beyond $748 \mathrm{~K}$, heat release due to the first stage ignition was observed in the compression stroke. Hence, the RCM ignition delay measurements at $P_{C}=40$ bar were restricted to compressed temperatures below $748 \mathrm{~K}$. In addition, all the pressure traces were examined against the corresponding inert runs by replacing $\mathrm{O}_{2}$ with $\mathrm{N}_{2}$ to ensure that heat release did not occur in the compression stroke, and the reactive runs with heat release in the compression stroke have been excluded from this study. For $\phi=0.5$ fuel/air mixtures at $P_{C}=40$ bar, pressure traces of both surrogates in Fig. 4 exhibited distinct two-stage ignition for compressed temperatures greater than $692 \mathrm{~K}$, while for compressed temperatures less than $692 \mathrm{~K}$ a gradual pressure rise was observed prior to hot ignition. For $\phi=0.3$ fuel/air mixtures at $P_{C}=40 \mathrm{bar}$, it is seen from Fig. 4 that both the surrogates exhibited distinct two-stages of ignition for the $T_{C}$ range investigated. It will be shown in due course that the pressure profile evolution can play an important role in assessing the performance of the surrogates in emulating the ignition propensity of gasoline.

It can be inferred from Figs. 3 and 4 that the total ignition delays decrease with increase in either pressure or equivalence ratio for the conditions investigated in this study. Interestingly, the first stage ignition delays were found to be less dependent on the equivalence ratios at $P_{C}=40$ bar, which is consistent with the results from Herzler et al. [19] and Kukkadapu et al. [10]. Table 3 provides the summary of the ignition delays measurements of the two surrogates conducted in this study at varying pressures, temperatures, and equivalence ratios. 


\subsection{Experimental Comparison of Autoignition Characteristics of RD387 and Surrogates}

Comparison of autoignition delay responses of gasoline (RD387) and its surrogates at compressed pressures of $P_{C}=20$ and 40 bar are shown in Figs. 5 and 6, respectively. As seen in Figs. 5(a), 6(a), and 6(c), the first stage ignition delays of the surrogates are consistently shorter than that of gasoline for all the tested conditions, thereby indicating that both surrogates have higher low-temperature reactivity than gasoline. The ranking of the low-temperature reactivity based on both the first-stage and overall ignition delay is Stanford A Surrogate > LLNL Surrogate > RD387, and such a ranking is consistent with our earlier study [16] conducted at stoichiometric conditions for the same fuels. Figure 5(b) shows that the total ignition delays of the surrogates at $P_{C}=20$ bar and $\phi=0.5$ fuel/air mixtures compare fairly well with those of gasoline for most compressed temperatures despite the substantial differences seen in Fig. 5(a) for the first stage ignition delays (when observed). Of the two surrogates, the ignition delays of the LLNL surrogate matched relatively better over the entire temperature range investigated at $P_{C}=20$ bar. It is to be noted that the differences between the ignition delays of the LLNL surrogate and RD387 appear to be more pronounced towards the end of the NTC regime. Similar observations were also made in [16] for stoichiometric fuel/air mixtures at $P_{C}=20$ bar.

Comparison of the total ignition delay responses of both surrogates for $\phi=0.5$ fuel/air mixtures at $P_{C}=40$ bar shown in Fig. 6(b) illustrates the same trend as the first stage ignition delays in Fig. 6(a). Furthermore, the difference in ignition delays appears to be less pronounced with increasing compressed temperatures. Figure 6(d) compares the total ignition delays of $\phi=0.3$ fuel/air mixtures at $P_{C}=40$ bar and shows the similar behavior as that discussed in Fig. 5(b) for $\phi=0.5$ fuel/air mixtures at $P_{C}=20$ bar. 
Based on these trends we may conclude that the two surrogates exhibit a higher reactivity in the low temperature regime, prompting a faster ignition (as can be observed in Fig. 5). For compressed conditions at which ignition proceeded through two distinct stages of ignition associated with a prolonged hot ignition induction time, the surrogates were found to replicate the ignition response of gasoline adequately. On the other hand, for the conditions only exhibiting single stage ignition behavior, controlled by the hot ignition chemistry, both surrogates closely replicate the ignition response of gasoline. Figure 7 demonstrates a comparison of pressure traces for RD387 and the two surrogates at different conditions to support the aforementioned inferences. Specifically, Figs. 7(a) and 7(b) correspond to the conditions where the fuel ignition is primarily controlled by the first stage ignition chemistry as well as the differences in the ignition delays of gasoline and its surrogates are seen to be substantial. In Figs. 7(c) and 7(d), although there are noticeable differences in the first stage ignition delays between gasoline and its surrogates, the surrogates replicate the total ignition delay times of gasoline to a good agreement and the prolonged hot ignition induction times of gasoline and the surrogates are noted. Further, Fig. 7(e) corresponds to the condition in the HTR, under which the ignition delays of the surrogates are identical and also agree very well with that of the gasoline and the difference is within the experimental uncertainty of $10 \%$.

To summarize the experimental findings in this section, the two surrogates investigated exhibit higher reactivity in the low temperature regime, but both closely replicate the ignition response of gasoline at high temperatures. An overall reactivity order is as follows: Stanford A Surrogate > LLNL Surrogate > RD387. The ability of the surrogates to accurately represent the ignition propensity of gasoline at temperatures other than in the LTR could be because of similar octane ratings as seen in Table 1 . It should be noted that the LLNL surrogate was specifically 
formulated targeting the octane values of the gasoline through a correlation based on its calculated total ignition delay times [6]. Sarathy et al. [15] in their recent work on surrogate experiments and modeling of FACE gasoline fuels also showed similar trends. In particular, it was found in [15] that their surrogate mixtures with similar octane ratings as FACE gasoline fuels exhibit identical reactivity for temperatures in the NTC and HTR, while differences in ignition delays were observed for temperatures in the LTR.

\section{Performance of Surrogate Model}

The gasoline surrogate model discussed here was developed at LLNL and includes 1389 species and 5935 reactions [17]. This chemical kinetic model was validated with ignition delays from shock tubes and rapid compression machines as well as speciation measurements in jet stirred reactors for surrogate constituents and surrogate mixtures [17].

RCM simulations, including the compression stroke and the heat loss effects during the compression and post-compression processes, were conducted to assess the performance of the chemical kinetic model. As described in $[18,20]$, the heat loss characteristics during the compression stroke and post EOC were deduced from the corresponding non-reactive experiment by replacing $\mathrm{O}_{2}$ with $\mathrm{N}_{2}$. Under the same operating conditions, it was noticed that the heat loss characteristics post EOC for the surrogates were identical to that of gasoline. It was shown in [21] that even with negligible exothermicity during the compression stroke, some radical initiation processes can begin to occur and subsequently affect the development of the radical pool after the end of compression. As such, the ignition processes observed in RCM experiments are responsive to the chemistry effects occurring during the compression stroke and the heat loss effects [21]. Therefore, the present RCM simulation is calculated based on the 
initial conditions prior to compression and the volume time-history deduced from the measured pressure history, corrected for heat loss, over the entire experiment. Figure 8 shows a comparison of experimental and simulated pressure traces exhibiting two-stage ignition phenomena for both surrogates at $\phi=0.5$ and $P_{C}=20$ bar, demonstrating reasonably good agreement for the specific conditions.

Similar to experiments, simulated ignition delays were determined relative to the end of compression and the onset of ignition was defined as the corresponding local maximum of the pressure rise rate post EOC. The performance of the gasoline surrogate model of [17] in predicting the ignition delays of the two surrogates at $\phi=0.5$ and $P_{C}=20$ bar is shown in Fig. 9. This is the first time that the LLNL model for the four-component LLNL surrogate and the threecomponent Stanford A surrogate has been tested under fuel-lean conditions important for low temperature combustion in advanced engines. It is seen from Fig. 9(a) that the first stage ignition delays of LLNL surrogate/air mixtures are under-predicted at compressed temperatures less than $700 \mathrm{~K}$ while over-predicted at compressed temperatures greater than $700 \mathrm{~K}$, but in general they are adequately predicted by the surrogate model. For the total ignition delays, Fig. 9(b) demonstrates an excellent agreement between experiments and simulations for the LLNL surrogate over the compressed temperature range investigated, including the positioning of NTC behavior response.

Figures 9(c) and 9(d) show the comparative results of the first stage and total ignition delays for Stanford A surrogate/air mixtures, respectively. The simulated first stage ignition delays are seen to exhibit an excellent agreement with the experimental data for compressed temperatures less than $730 \mathrm{~K}$, while over-prediction from the surrogate model is noted at a compressed temperature of $761 \mathrm{~K}$. For the total ignition delays (Fig. 9(d)), the surrogate model performs well 
in capturing the experimental results at high temperatures (above $820 \mathrm{~K}$ ), but under-predicts ignition delays for lower temperatures. It is interesting to examine the case at $730 \mathrm{~K}$ where the first-stage ignition delay is predicted well, but the second-stage ignition time is under-predicted. This discrepancy could be caused by higher pressure rise during first stage ignition predicted by the surrogate model at $730 \mathrm{~K}$ compared to the experiment, as shown in Fig. 8(b). A higher pressure rise from first stage ignition would shorten the induction time for the subsequent hot ignition. The higher pressure rise for the first stage is not seen when comparing to the LLNL surrogate at similar conditions, as shown in Fig. 8(a).

The reason why the higher pressure rise is seen for the Stanford A surrogate but not the LLNL surrogate may be due to issues with the chemical kinetic model for the surrogates. The LLNL surrogate contains the four components: $n$-heptane, iso-octane, toluene, and 2-pentene. It is known that iso-octane, toluene, and 2-pentene produce unreactive species that slow the reactivity of the more reactive fuel component $n$-heptane. In the model of the LLNL surrogate, these unreactive species produce just the right amount of inhibition effect on the reactive fuel component $n$-heptane. In the Stanford A surrogate, 2-pentene is removed and the model is too reactive at relevant conditions. Perhaps too much of the inhibition effect in the model of the LLNL surrogate is due to 2-pentene rather than iso-octane or toluene. This work therefore indicates that improvements to the component submodels may be needed to obtain agreement within the error bars in Fig. 9. Improvements to the $n$-heptane and iso-octane submodels are currently being pursued.

Another reason for the discrepancy in the pressure rise after the first-stage ignition for the Stanford A surrogate could be due to pressure-induced gas flows that occur from the main chamber to the crevice volume. As mentioned earlier, the RCM employed in the present study 
uses a creviced piston design to suppress the roll-up vortex effects. Mittal and Chomier [22] recently showed that mass transfer into the piston crevice could lower the pressure rise from first stage ignition. However, since the ratio between the crevice volume and the reaction chamber volume for the condition shown in Fig. 8(b) is in the order of $8.3 \%$, the effect of mass transfer discussed in [22] is expected to be minimal and the observed differences in the first-stage pressure rise could be still chemical in origin. A final observation about Fig. 9 is that the surrogate model is seen to reproduce the positioning of the NTC regime in the present RCM experiments for both the surrogates, as shown in Figs. 9(b) and 9(d).

A comparison between the ignition delays from experiments and simulations at $P_{C}=40$ bar is shown in Fig. 10. The first stage and total ignition delays of the surrogates were found to be over-predicted by the surrogate model at $P_{C}=40$ bar for most of the compressed temperatures investigated. However, the surrogate model was noted to capture the qualitative behavior of surrogates at $P_{C}=40$ bar very well. For instance, the simulations show that the first stage ignition delays of the surrogates are weakly dependent on the equivalence ratio and are primarily controlled by temperature, as observed in the experiments. In addition, as the experimental results, the simulated total ignition delays decrease with increase in equivalence ratio.

\section{Chemical Kinetic Analysis}

To identify the controlling chemistry for autoignition, brute force sensitivity analyses have been conducted to calculate the sensitivities of reactions to first stage and total ignition delays using the LLNL surrogate. Sensitivity analyses were carried out with adiabatic constant volume simulations based on the gasoline surrogate model of [17]. For the analysis, the pre-exponential Arrhenius factors of both the forward and backward reaction rates were simultaneously 
multiplied by a factor of two and the sensitivity coefficients defined as $S_{\tau 1}=\frac{\tau_{1}(2 \mathrm{~A})-\tau_{1}(\mathrm{~A})}{\tau_{1}(\mathrm{~A})} \times$ 100 and $S_{\tau}=\frac{\tau(2 \mathrm{~A})-\tau(\mathrm{A})}{\tau(\mathrm{A})} \times 100$ for $\tau_{1}$ and $\tau$, respectively, were obtained for all of the reactions in the surrogate model. In these expressions, $\tau_{1}$ is the first stage ignition delay, $\tau$ is the total ignition delay, and "A" represents the forward and backward pre-exponential Arrhenius factors. A negative (positive) sensitivity coefficient implies that doubling of the particular reaction rate promotes (retards) ignition process. In the adiabatic constant volume simulations, the total ignition delay was defined as the time at which the local temperature is $400 \mathrm{~K}$ above the initial temperature. For the conditions exhibiting two-stage ignition response, the first stage ignition delay was defined as the time with $30 \mathrm{~K}$ increase from the initial temperature, which is the typical case observed in simulations. For instance, the temperature rise due to first sage ignition for an initial temperature of $780 \mathrm{~K}$ was found to be around $50 \mathrm{~K}$. From these preliminary simulations, a $30 \mathrm{~K}$ rise in temperature was used to define the first stage ignition delays in the following chemical kinetic analyses. Since the temperature rise due to first stage ignition decreases with increase in initial temperature, care needs to be taken in defining first stage ignition delay at time corresponding to a certain temperature raise. The sensitivity analyses were conducted to obtain sensitivity coefficients of total and first stage ignition delays at varying initial temperatures, initial pressures, and equivalence ratios. These coefficients obtained from the current sensitivity analysis would aid in improvement of the surrogate model.

Two sets of sensitivity analyses were conducted, one each at initial pressures of 20 bar (Figs. 11 and 12) and 40 bar (Figs. 13 and 14). The analysis at an initial pressure of 20 bar was conducted with initial temperatures of $680 \mathrm{~K}$ and $780 \mathrm{~K}$ for the $\phi=0.5$ fuel/air mixtures along with an initial temperature of $780 \mathrm{~K}$ for the $\phi=1$ fuel/air mixture. The choice of the two different initial temperatures for $\phi=0.5$ was based on the comparison shown in Fig. 9(a) for the first stage 
ignition delays, as the surrogate model was found to be more (less) reactive than experiments at temperatures less (greater) than $700 \mathrm{~K}$. Furthermore, the total ignition delays predicted by the surrogate model was shown in Fig. 9(b) to agree well with experimental values despite significant differences in the first stage ignition delays at temperatures greater than $700 \mathrm{~K}$. In order to understand the reason for this observed behavior, sensitivity analyses were conducted at $680 \mathrm{~K}$ and $780 \mathrm{~K}$. In addition, a sensitivity analysis for the $\phi=1$ condition at $780 \mathrm{~K}$ was carried out to capture the effect of equivalence ratio.

The second set of analyses at 40 bar was conducted with an initial temperature of $735 \mathrm{~K}$ for fuel/air equivalence ratios of both $\phi=0.5$ and 1 . This condition was chosen in view of the significant discrepancy between experimental and simulated results shown in Figs. 10(a) and 10(b). Hence, information about $S_{\tau 1}$ and $S_{\tau}$ shown in Figs. 11-14 at these varying conditions could help in identifying the important reactions whose reactions rate could be further evaluated in order to improve the fidelity of the surrogate model. It is also noted that a cutoff value of 5\% change in ignition delays was chosen for plotting the sensitivity results in Figs. 11-14. Table 4 shows the nomenclature and site specificity of some species discussed in the following.

Figure 11 shows the sensitivity coefficients for the first stage ignition delays at an initial pressure of 20 bar with varying initial temperatures and equivalence ratios. For the case of $680 \mathrm{~K}$ and $\phi=0.5$, the reactions of parent fuel molecules and $\mathrm{OH}$ appear to be the most sensitive set of reactions. Since the reactions of toluene with $\mathrm{OH}$ produce radicals which are not reactive at such low temperatures, they are chain-terminating in nature and hence exhibit positive sensitivity. On the other hand, as the reactions of $n$-heptane with $\mathrm{OH}$ lead to the production of $n$-heptyl isomers, all of the $n$-heptyl isomers initiate the chain-branching low-temperature reactions and hence these reactions exhibit negative sensitivity. For the reactions of iso-octane with $\mathrm{OH}$, their 
sensitivity coefficients exhibit site specificity. Specifically, the H-abstraction reactions for isooctane by $\mathrm{OH}$ leading to the formation of primary iso-octyl $\left(a-\mathrm{C}_{8} \mathrm{H}_{17}, d-\mathrm{C}_{8} \mathrm{H}_{17}\right)$ and secondary iso-octyl $\left(b-\mathrm{C}_{8} \mathrm{H}_{17}\right)$ radicals exhibit negativity sensitivity, while those leading to the formation of tertiary iso-octyl $\left(c-\mathrm{C}_{8} \mathrm{H}_{17}\right)$ radicals exhibit positive sensitivity, meaning longer ignition delay times. Moreover, all of the four iso-octyl radicals react with oxygen forming iso-octylperoxy ( $a$ $\left.\mathrm{C}_{8} \mathrm{H}_{17} \mathrm{O}_{2}, b-\mathrm{C}_{8} \mathrm{H}_{17} \mathrm{O}_{2}, c-\mathrm{C}_{8} \mathrm{H}_{17} \mathrm{O}_{2}, d-\mathrm{C}_{8} \mathrm{H}_{17} \mathrm{O}_{2}\right)$ radicals. Further, $a-\mathrm{C}_{8} \mathrm{H}_{17} \mathrm{O}_{2}, b-\mathrm{C}_{8} \mathrm{H}_{17} \mathrm{O}_{2}$, and $d-$ $\mathrm{C}_{8} \mathrm{H}_{17} \mathrm{O}_{2}$ undergo isomerization reactions predominantly through six-member transition state structures to form hydroperoxy iso-octyl radicals. These hydroperoxy iso-octyl radicals subsequently facilitate chain-branching reactions that lead to the formation of ketohydroperoxides. Therefore, the $\mathrm{H}$-abstraction reactions leading to the formation of $a-\mathrm{C}_{8} \mathrm{H}_{17}$, $b-\mathrm{C}_{8} \mathrm{H}_{17}$, and $d-\mathrm{C}_{8} \mathrm{H}_{17}$ exhibit negative sensitivity. In contrast, $c-\mathrm{C}_{8} \mathrm{H}_{17} \mathrm{O}_{2}$ does not lead to formation of ketohydroperoxides. $c-\mathrm{C}_{8} \mathrm{H}_{17} \mathrm{O}_{2}$ is predominantly consumed via two sets of reactions, the first involves the conversion of $c-\mathrm{C}_{8} \mathrm{H}_{17} \mathrm{O}_{2}$ to di-isobutylene and $\mathrm{HO}_{2}$. The second set of reactions involves conversion of $c-\mathrm{C}_{8} \mathrm{H}_{17} \mathrm{O}_{2}$ to cyclic ether and $\mathrm{OH}$ radical. The whole reaction scheme that involves $c-\mathrm{C}_{8} \mathrm{H}_{17}$ is not chain branching and acts as $\mathrm{OH}$ radical scavenger. Therefore, the reaction between iso-octane and $\mathrm{OH}$ leading to the formation of $c-\mathrm{C}_{8} \mathrm{H}_{17}$ exhibits a positive sensitivity.

At the initial condition of $780 \mathrm{~K}$ and 20 bar, comparison of $S_{\tau 1}$ in Fig. 11 for $\phi=0.5$ and 1.0 shows that similar classes of reactions control the first stage chemistry, indicating that increasing the equivalence ratio did not affect reaction classes identified by sensitivity analysis. Also, the magnitudes of the sensitivity coefficients at $780 \mathrm{~K}$ are significantly larger (by a factor of $2-4$ for the most sensitive reactions) than the previously discussed results at $680 \mathrm{~K}$. This means that the choice of rate parameters has more of an influence at $780 \mathrm{~K}$ than at $680 \mathrm{~K}$. The $\mathrm{H}$-abstraction 
reactions from parent fuel molecules by $\mathrm{OH}$ radicals and the isomerization reactions of alkylperoxy radicals continue to be the major reaction classes that control the first stage ignition even at $780 \mathrm{~K}$. Other important classes of reactions that control first stage ignition chemistry are the olefin producing concerted elimination reactions of alkylperoxy radicals and $\beta$-scission reactions of hydroperoxy alkyl radicals. At $780 \mathrm{~K}$, since the concerted elimination and $\beta$-scission reactions leading to the formation of less reactive $\mathrm{HO}_{2}$ and olefins compete with chain-branching low-temperature reactions, these olefin producing pathways can be termed chain-terminating at these conditions and hence exhibit positive sensitivity coefficients. Comparison of the sensitivity coefficients thus suggests that in order to improve the overall first stage ignition delay predictions (over-prediction at $780 \mathrm{~K}$ in Fig. 9(a)), the rate coefficients of the concerted elimination reaction of alkylperoxy radicals and the $\beta$-scission reactions of hydroperoxy alkyl radicals need to be reduced.

Figure 12 shows the sensitivity coefficients of the total ignition delays at 20 bar for varying initial temperatures and equivalence ratios. For $\phi=0.5$, comparison of the sensitivity coefficients at $680 \mathrm{~K}$ and $780 \mathrm{~K}$ demonstrates that the $\mathrm{H}$-abstraction reactions from parent fuel molecules by $\mathrm{OH}$ radicals, the isomerization reactions of alkylperoxy radicals and peroxyalkylhydroperoxide radicals, and the reactions involving smaller species control the total ignition delay time. It is interesting to note that the rate constant for dissociation of hydrogen peroxide $\left(\mathrm{H}_{2} \mathrm{O}_{2}\right)$ is quite important in determining the total ignition delay time, but not the first stage ignition time. Hydrogen peroxide starts to build up about the time of the first stage ignition and then rapidly dissociates to form two reactive $\mathrm{OH}$ radicals when the temperature reaches about $1000 \mathrm{~K}$ [23]. The rate constant in the LLNL mechanism [17] used in this study was a pressure-dependent fit in Troe form with a low-pressure rate constant from Warnatz [24] and a high-pressure rate constant 
from Brouwer et al. [25]. However, this rate constant has been subsequently updated by Troe [26] and is about 1.7 times higher than the previous rate constant at the conditions in Fig. 12, which would reduce the total ignition delay time by $18 \%$ at these conditions. We are currently evaluating new $\mathrm{C}_{1}-\mathrm{C}_{4}$ base chemistry from Burke et al. [27], which incorporates this updated rate constant, for use in our hydrocarbon mechanisms.

Similar to the first stage ignition delay sensitivity, the total ignition delay at $780 \mathrm{~K}$ is sensitive to the concerted elimination reactions of alkylperoxy radicals and the $\beta$-scission reactions of hydroperoxy alkyl radicals. It is noted that the $S_{\tau}$ values of these olefin producing reactions are positive and comparable to their $S_{\tau 1}$ values. Thus, any change in reaction rates of these olefin producing pathways to reduce the first stage ignition delays for better agreement with the experimental data would reduce the total ignition delays as well, which will deteriorate the performance of the surrogate model in closely matching the experimental total ignition delays shown in Fig. 9(b).

Figure 13 shows the sensitivity coefficients for the first stage ignition delays at initial conditions of 40 bar and $735 \mathrm{~K}$ for fuel/air mixtures of $\phi=0.5$ and 1 . It can be observed in Fig. 13 that similar set of reactions appear to control first stage ignition for both equivalence ratios but the off-stoichiometric mixture exhibits higher sensitivity coefficients. The reactions of fuel molecules with $\mathrm{OH}$ radicals and isomerization of alkylperoxy radicals are seen to be the most sensitive set of reactions, reasons for which have been explained earlier. Additionally, similar set of reactions were found to be sensitive for stoichiometric mixtures at 20 bar in [10], indicating that the controlling chemistry does not vary much with changes in either pressure or equivalence ratio. Figure 14 shows the sensitivity coefficients for the total ignition delays at initial conditions of 40 bar and $735 \mathrm{~K}$ for varying equivalence ratios. At the stoichiometric condition, the reactions 
between parent fuel molecules and $\mathrm{OH}$ radicals along with the isomerization reactions of alkylperoxy radicals and peroxyalkylhydroperoxide radicals are found to be the controlling chemistry for total ignition delays. These sensitive reactions are also seen to be important for the total ignition delays at off-stoichiometric conditions. In addition, the reactions involving smaller intermediate species such as $\mathrm{HO}_{2}, \mathrm{CH}_{3} \mathrm{O}_{2}, \mathrm{H}_{2} \mathrm{O}_{2}$, etc. exhibit higher sensitivities for offstoichiometric mixtures. In particular, the reaction of $\mathrm{H}_{2} \mathrm{O}_{2}$ with $\mathrm{O}_{2}$ to make two $\mathrm{HO}_{2}$ radicals inhibits the transition to the second stage ignition for the off-stoichiometric case. This could partially explain the difference observed in experiments for the pressure evolution from first stage ignition event to hot ignition, namely a gradual pressure rise for stoichiometric mixtures versus a distinct two-stage response for off-stoichiometric mixtures, as shown in Fig. 15. Also for off-stoichiometric mixtures, the results shown in Fig. 13 indicate more sensitivity to the reactions affecting the first-stage ignition. From the sensitivity coefficient results of Figs. 13 and 14, it appears that for improving the performance of the surrogate model at high pressures and low temperatures investigated in this study, the reaction rates of the reactions of fuel $+\mathrm{OH}$ as well as the isomerization reactions of alkylperoxy radicals and peroxyalkylhydroperoxide radicals may need to be modified. However, any changes to the reactions rates of fuel $+\mathrm{OH}$ to improve the low temperature reactivity may in turn affect the performance of the surrogate model at high temperatures. Therefore, it may be required to change various sensitive reactions in concert so as to change the reactivity in the desired way over the whole temperature range.

These brute force sensitivity analysis results shown in Figs. 11-14 suggest that simple modifications to a particular reaction class may not be sufficient to improve the performance of the surrogate model at low temperatures, as reaction rates of various reactions important at low temperatures need to be re-evaluated and updated. A recent study by Karwat et al. [28] has 
shown an improvement in the performance of an $n$-heptane model when the reaction rates of some low temperature chemistry were modified with those from a theoretical study of Villano et al. [29]. Hence, further investigation, similar to that of [28,30], is warranted for developing a comprehensive gasoline surrogate model.

\section{Conclusions}

Autoignition characteristics of two gasoline surrogates, the four-component LLNL surrogate and the three-component Stanford A surrogate, were experimentally investigated using a rapid compression machine, with a special emphasis on lean fuel/air mixtures at elevated pressure and low temperature conditions. Comparison of the first stage and total ignition delays of the two surrogates and those of the target research grade gasoline (RD387) has been conducted. It was found that the first stage ignition delays of the surrogates were shorter than those of RD387 with the LLNL surrogate showing a better agreement with RD387. Despite the differences in the first stage ignition delays, the total ignition delays of the surrogates exhibited a good agreement with those of RD387. In general, the LLNL surrogate performed better in matching the autoignition characteristics of RD387.

Simulations were also conducted to assess the performance of the LLNL gasoline surrogate model [17] in predicting the ignition delays of both surrogates. This surrogate model was shown to predict the total ignition delays to good agreement at 20 bar while its first stage ignition delay prediction was also deemed adequate despite some discrepancies. However, the surrogate model was found to be less reactive than the experiments in the low temperature regime at a higher compressed pressure of 40 bar, and hence would need further improvements. Brute force sensitivity analyses were further conducted at varying pressures, temperatures, and equivalence 
ratios to identify the key reactions controlling autoignition. The sensitivity results showed that the reaction rates of the key low temperature chemistry may need to be re-evaluated and updated in order to develop a comprehensive chemical kinetic model.

Furthermore, in addition to ignition delay measurements, experimental determination of time-dependent species concentrations and temperature history during the induction period, as conducted in [e.g., 28,30-32], will provide useful insights into fundamental autoignition chemistry and offer the next level of rigor for model comparisons. However, it is challenging to extend the applications of the currently available ex-situ and in-situ diagnostics to high pressures (say 20-50 bar) and large hydrocarbons relevant to surrogate components of transportation fuels. Therefore, development of advanced diagnostic techniques for facilitating speciation and temperature measurements in an RCM under engine-like conditions is required, which is also a part of our ongoing efforts.

\section{Acknowledgements}

The work at UConn was supported by the National Science Foundation under Grant No. CBET1402231. The work at LLNL was supported by the U.S. Department of Energy, Vehicle Technologies Office (program managers Gurpreet Singh and Leo Breton) and performed under the auspices of the U.S. Department of Energy by Lawrence Livermore National Laboratory under Contract DE-AC52-07NA27344. 


\section{References}

1. R.D. Reitz, Combust. Flame 160 (2013) 1-8.

2. W.J. Pitz., N.P. Cernansky, F.L. Dryer, F.N. Egolfopoulos, J.T. Farrell, D.G. Friend, H. Pitsch, SAE 2007 Transactions Journal of Passenger Cars - Mechanical Systems, SAE 2007-01-0175.

3. M. Chaos, Z. Zhao, A. Kazakov, P. Gokulakrishnan, M. Angioletti, F.L. Dryer, 5th US Combustion Meeting, Paper E26, March 25-28, 2007.

4. B.M. Gauthier, D.F. Davidson, R.K. Hanson, Combust. Flame 139 (2004) 300-311.

5. G. Vanhove, G. Petit, R. Minetti, Combust. Flame 145 (2006) 521-532.

6. M. Mehl, J.Y. Chen, W.J. Pitz, S.M. Sarathy, C.K. Westbrook, Energy Fuels 25 (11), (2011) 5215-5223.

7. C.V. Naik, W.J. Pitz, M. Sjöberg, J.E. Dec, J. Orme, H.J. Curran, J.M. Simmie, C.K. Westbrook, SAE 2005-01-3741.

8. D.B. Lenhert, D.L. Miller, N.P. Cernansky, K.G. Owens, Combust. Flame 156 (2009) 549564.

9. G. Mittal, C.J. Sung, Combust. Flame 155 (2008) 431-439.

10. G. Kukkadapu, K. Kumar, C.J. Sung, M. Mehl, W.J. Pitz, Combust. Flame 159 (2012) 3066-3078.

11. M. Sjöberg, J. E. Dec, W. Hwang, SAE 2007-01-0207.

12. J.E. Dec, Y. Yang, N. Dronniou, SAE 2011-01-897.

13. S. Jerzembeck, N. Peters, SAE 2007-01-2006.

14. G.R. Tian, H.L. Daniel, H. Xu, S. Shuai, P. Richards, Energy Fuels 24 (2010) 3898-3905.

15. S.M. Sarathy, G. Kukkadapu, M. Mehl, W. Wang, T. Javed, S. Park, M.A. Oehlschlaeger, A. Farooq, W.J. Pitz, C.J. Sung, Proc. Combust. Inst. 35 (2014), in press. [http://dx.doi.org/10.1016/j.proci.2014.05.122] 
16. G. Kukkadapu, K. Kumar, C.J. Sung, M. Mehl, W.J. Pitz, Proc. Combust. Inst. 34 (2013) 345-352.

17. M. Mehl, W.J. Pitz, C.K. Westbrook, H.J. Curran, Proc. Combust. Inst. 33 (2011) 193-200.

18. G. Mittal, C.J. Sung, Combust. Sci. Technol. 179 (2007) 497-530.

19. J. Herzler, L. Jerig, P. Roth, Proc. Combust. Inst. 30 (2005) 1147-1153.

20. K. Kumar, G. Mittal, C.J. Sung, Combust. Flame 156 (2009) 1278-1288.

21. G. Mittal, M. Chaos, C.J. Sung, F.L. Dryer, Fuel Processing Tech. 89 (2008) 1244-1254.

22. G. Mittal, M. Chomier, Combust. Flame 161 (2014) 398-404.

23. C.K. Westbrook, Proc. Combust. Inst. 28 (2000) 1563-1577.

24. J. Warnatz, in Combustion Chemistry, ed. W.C. Gardiner Jr., Springer-Verlag, New-York, 1984, pp. 197-360.

25. L. Brouwer, C.J. Cobos, J. Troe, H.R. Dubal, F.F. Crim, J. Chem. Phys. 86 (1987) 61716182.

26. J. Troe, Combust. Flame 158 (4) (2011) 594-601.

27. S.M. Burke, W. Metcalfe, O. Herbinet, F. Battin-Leclerc, F.M. Haas, J. Santner, F.L. Dryer, H.J. Curran, Combust. Flame 161 (11) (2014) 2765-2784.

28. D.M.A. Karwat, S.W. Wagnon, M.S. Wooldridge, C.K. Westbrook, Combust. Flame 160 (2013) 2693-2706.

29. S.M. Villano, K.L. Huynh, H.H. Carstensen, A.M. Dean, J. Phys. Chem. A 115 (2011) $13425-13442$.

30. M.F. Campbell, S. Wang, C.S. Goldenstein, R.M. Spearrin, A.M. Tulgestke, L.T. Zaczek, D.F. Davidson, R.K. Hanson, Proc. Comb. Inst,, 35 (2014), in press, [http:// doi:10.1016/j.proci.2014.05.001]

31. M. Uddi, A.K. Das, C.J. Sung, Applied Optics 51 (22) (2012) 5464-5476.

32. A.K. Das, M. Uddi, C.J. Sung, Combust. Flame 159 (12) (2012) 3493-3501. 


\section{List of Figures}

Figure 1 Plot showing the definitions of end of compression (time=0), first stage ignition delay $\left(\tau_{1}\right)$, and total ignition delay $(\tau)$.

Figure 2 Plot showing the repeatability of the present RCM data.

Figure 3 Plots showing the ignition delay measurements and the representative pressure traces recorded at various conditions at $P_{C}=20$ bar.

Figure 4 Plots showing the ignition delay measurements and the representative pressure traces recorded at various conditions at $P_{C}=40$ bar.

Figure 5 Comparison of first stage and total ignition delays of LLNL and Stanford A surrogates (current work) with those of RD387 from [10] at $P_{C}=20$ bar.

Figure 6 Comparison of first stage and total ignition delays of LLNL and Stanford A surrogates (current work) with those of RD387 from [10] at $P_{C}=40$ bar.

Figure 7 Comparison of experimental pressure trace profiles of LLNL and Stanford A surrogates (current work) with those of RD387 from [10] at varying conditions.

Figure 8 Comparison of experimental and simulated pressure traces for LLNL and Stanford A surrogates at $P_{C}=20$ bar.

Figure 9 Arrhenius plots showing comparisons of experimental and simulated ignition delays for LLNL and Stanford A surrogates at $P_{C}=20$ bar.

Figure 10 Arrhenius plots showing comparisons of experimental and simulated ignition delays for LLNL and Stanford A surrogates at $P_{C}=40$ bar.

Figure 11 Brute force sensitivity coefficients for first stage ignition delays of LLNL surrogate at varying initial temperatures and equivalence ratios with initial pressure of 20 bar. 
Figure 12 Brute force sensitivity coefficients for total ignition delays of LLNL surrogate at varying initial temperatures and equivalence ratios with initial pressure of 20 bar.

Figure 13 Brute force sensitivity coefficients for first stage ignition delays of LLNL surrogate at varying equivalence ratios with initial conditions of 40 bar and $735 \mathrm{~K}$.

Figure 14 Brute force sensitivity coefficients for total ignition delays of LLNL surrogate at varying equivalence ratios with initial conditions of 40 bar and $735 \mathrm{~K}$.

Figure 15 Comparison of experimental pressure traces for LLNL surrogate with equivalence ratios of $\phi=0.5$ and 1 at $P_{C}=40$ bar and $T_{C}=724 \mathrm{~K}$.

\section{List of Tables}

Table 1 Property comparison of gasoline and surrogates investigated in this study.

Table 2 Pre-heat conditions of the present and previous [10,16] RCM experiments.

Table 3 Summary of ignition delay data.

Table 4 Nomenclature and site specificity of some species. 


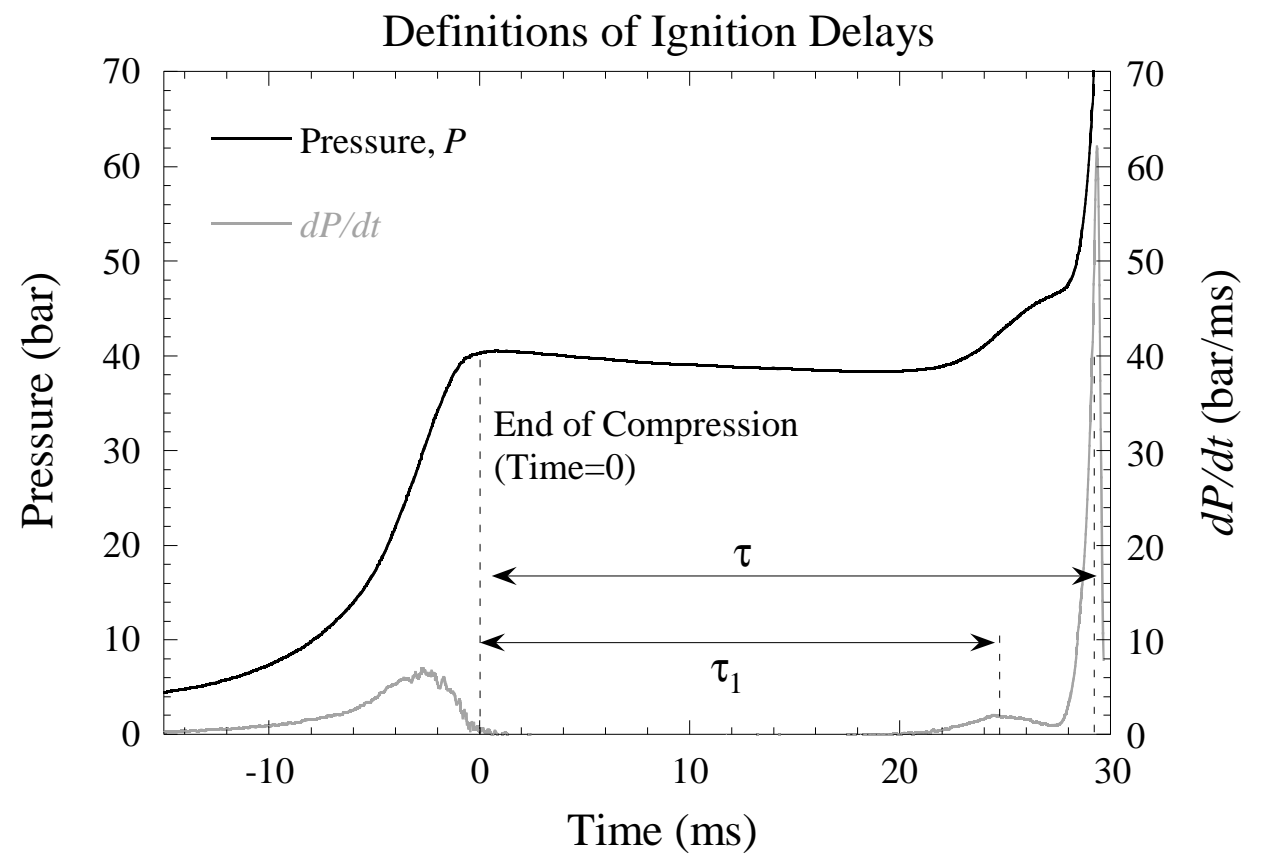

Figure 1 


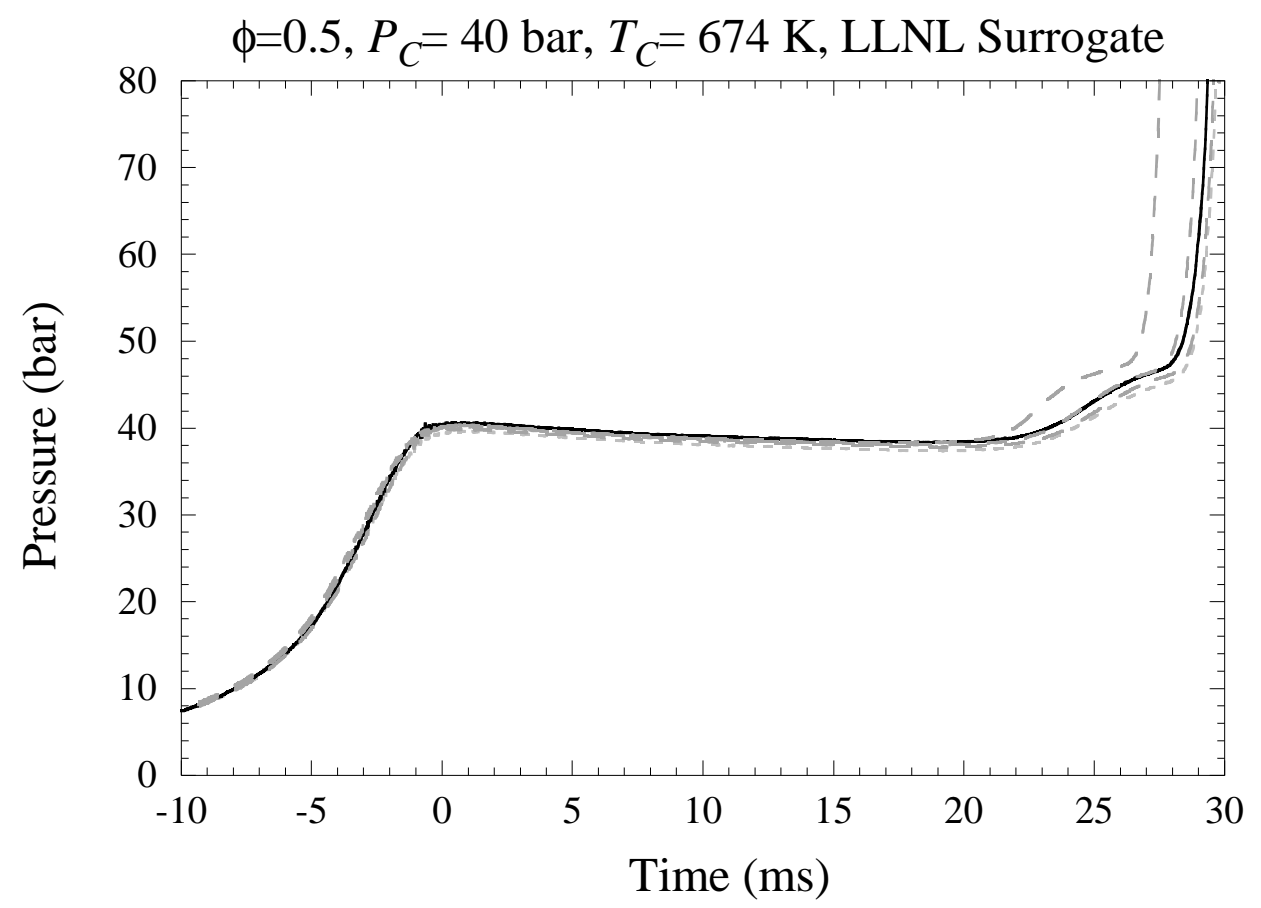

Figure 2 

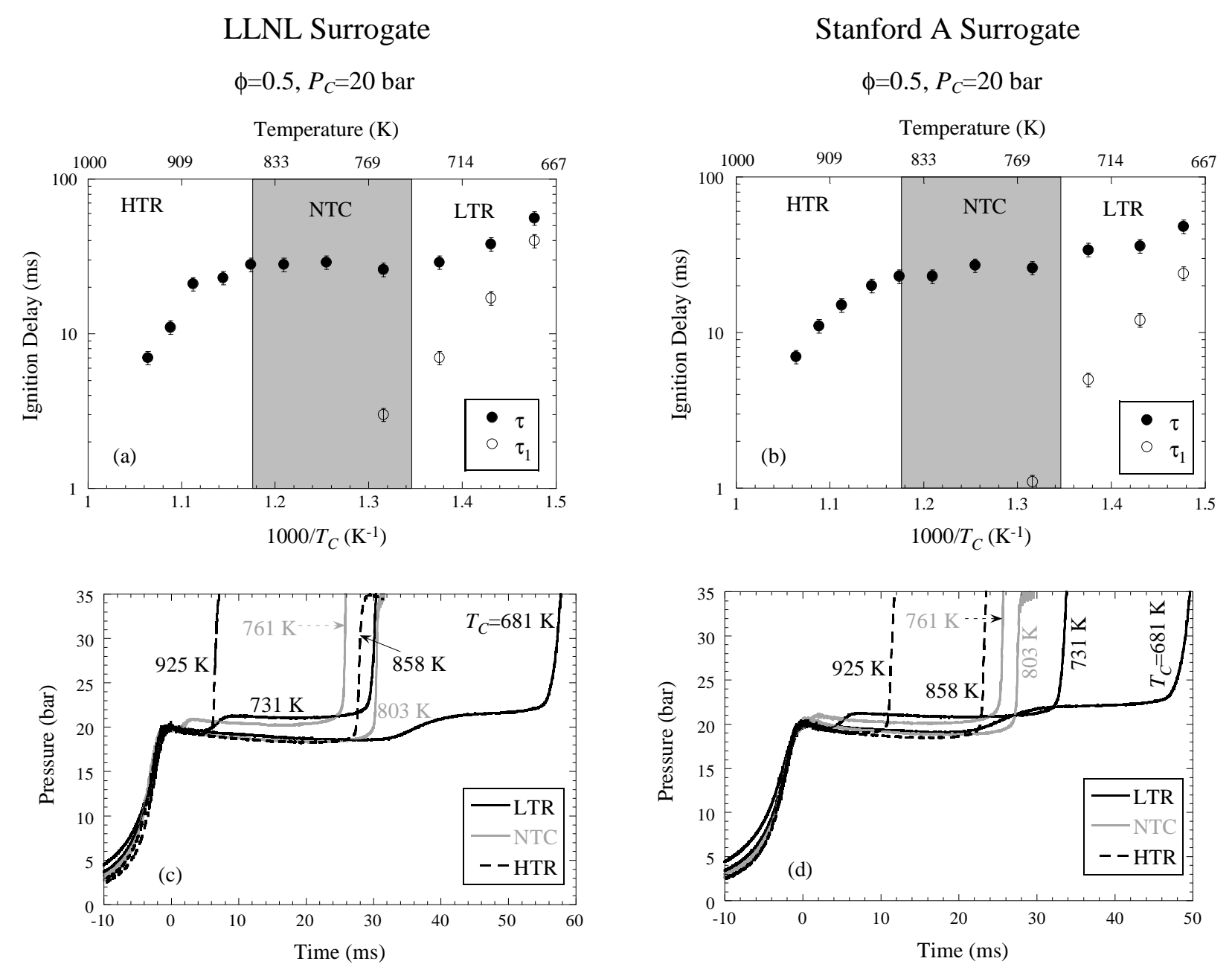

Figure 3 


\section{LLNL Surrogate}

$$
P_{C}=40 \text { bar }
$$
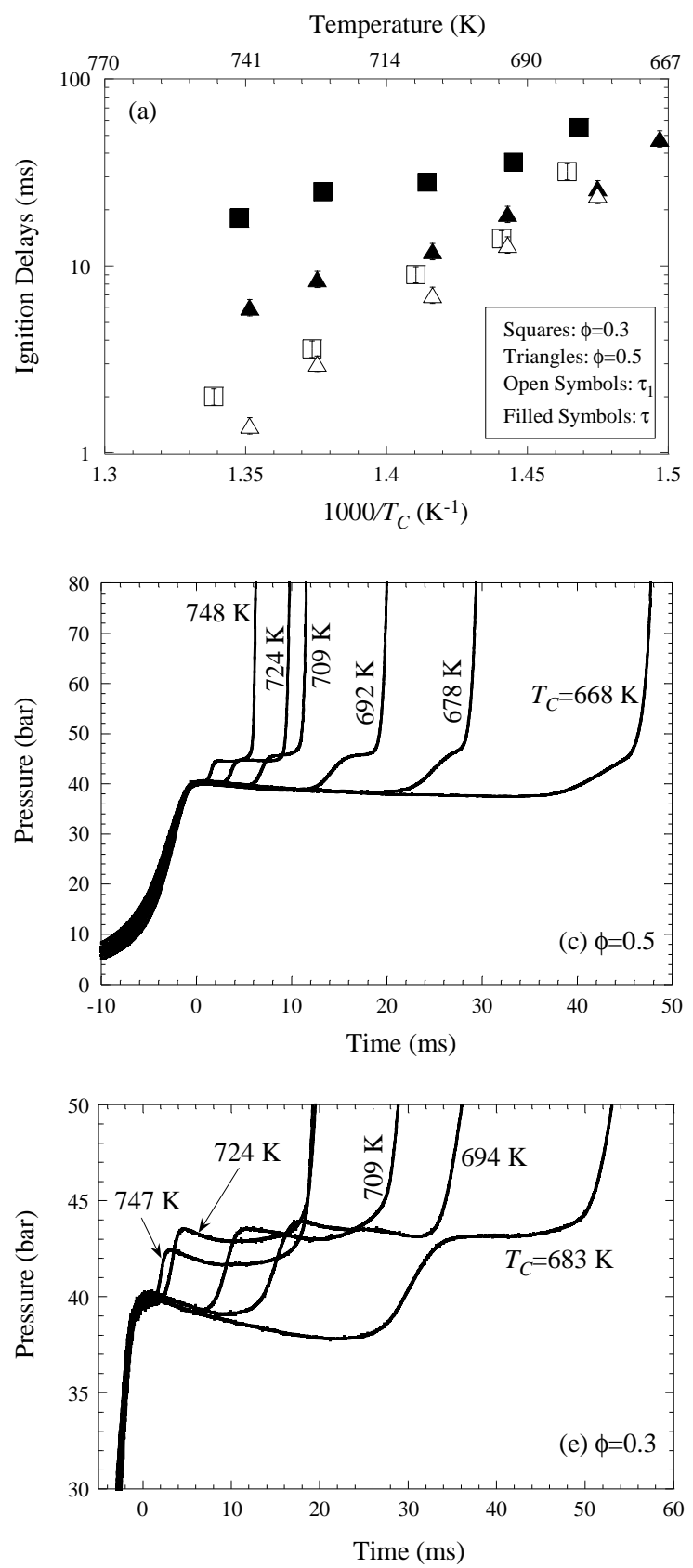

\section{Stanford A Surrogate}
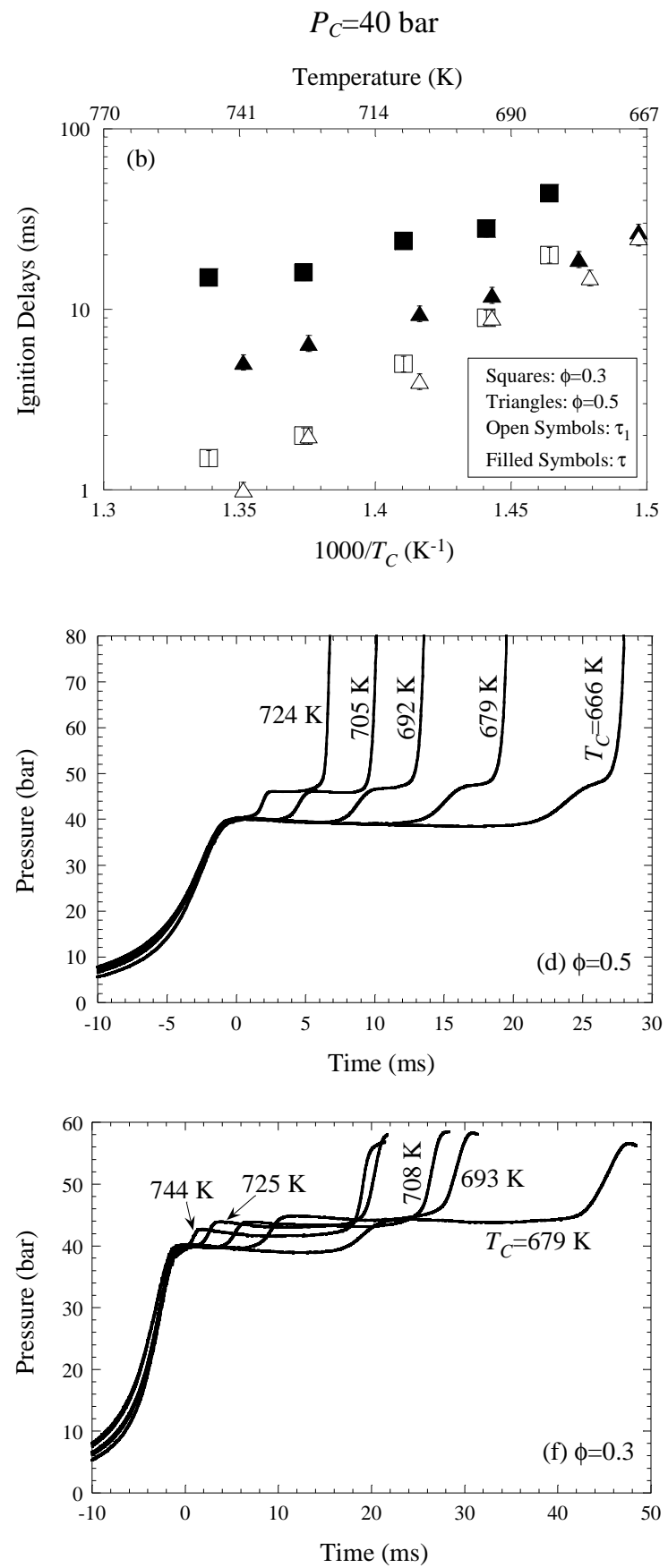

Figure 4 

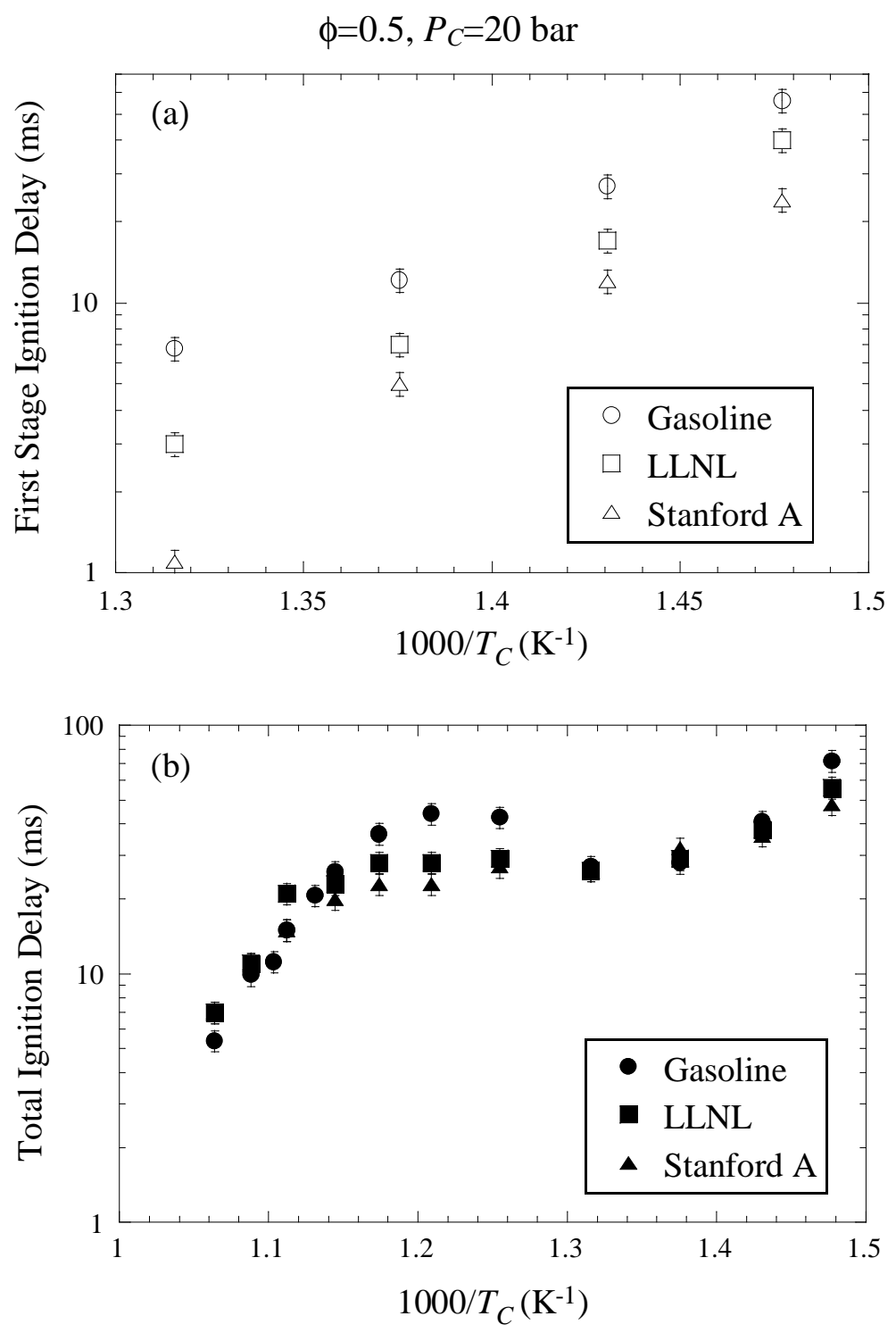

Figure 5 
(a) $\phi=0.5, P_{C}=40$ bar

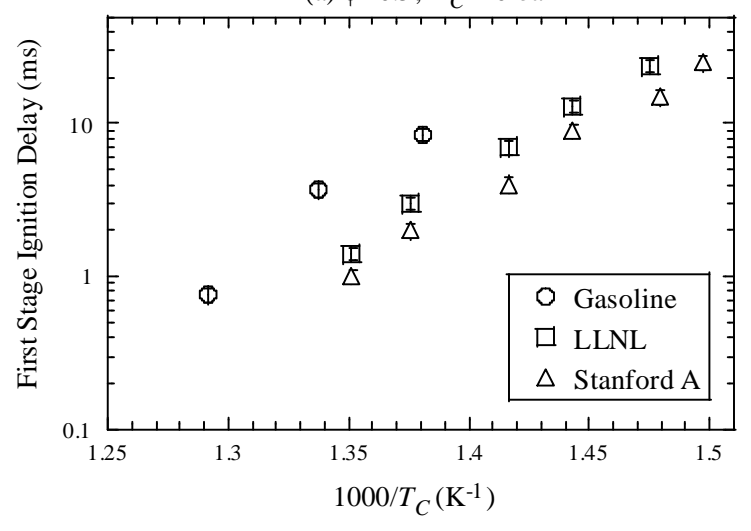

(c) $\phi=0.3, P_{C}=40 \mathrm{bar}$

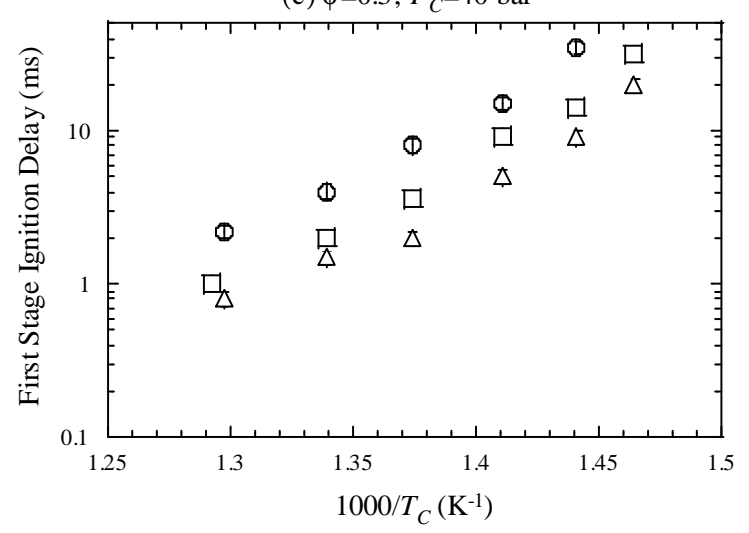

(b) $\phi=0.5, P_{C}=40 \mathrm{bar}$

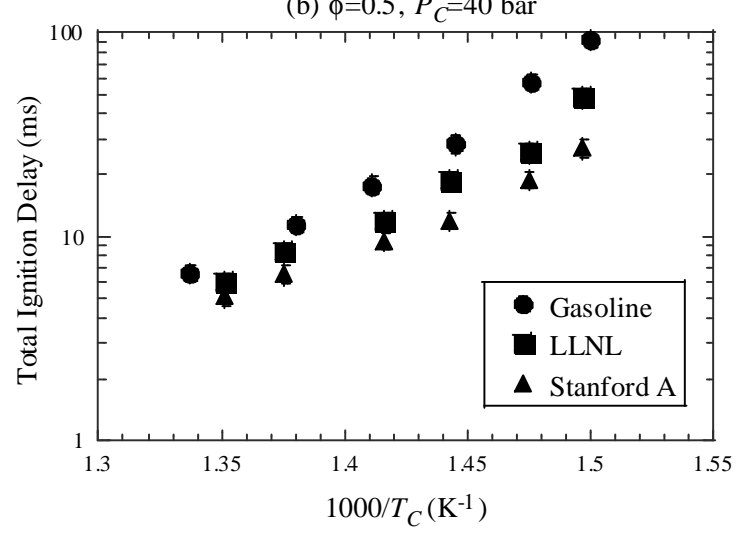

(d) $\phi=0.3, P_{C}=40$ bar

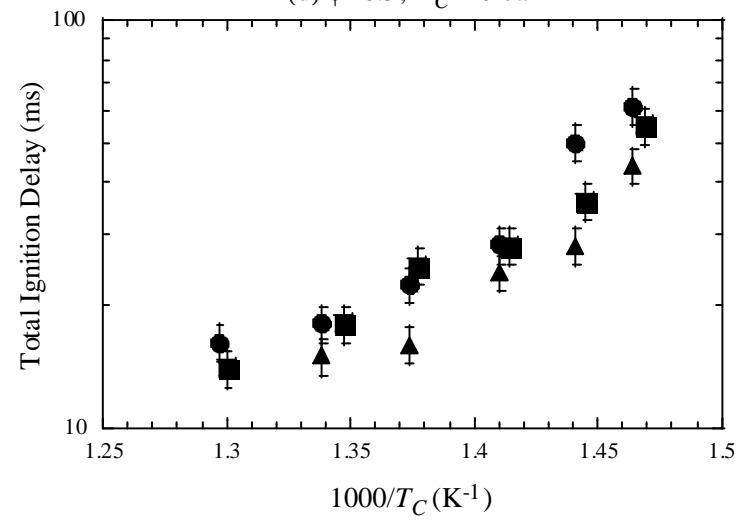

Figure 6 

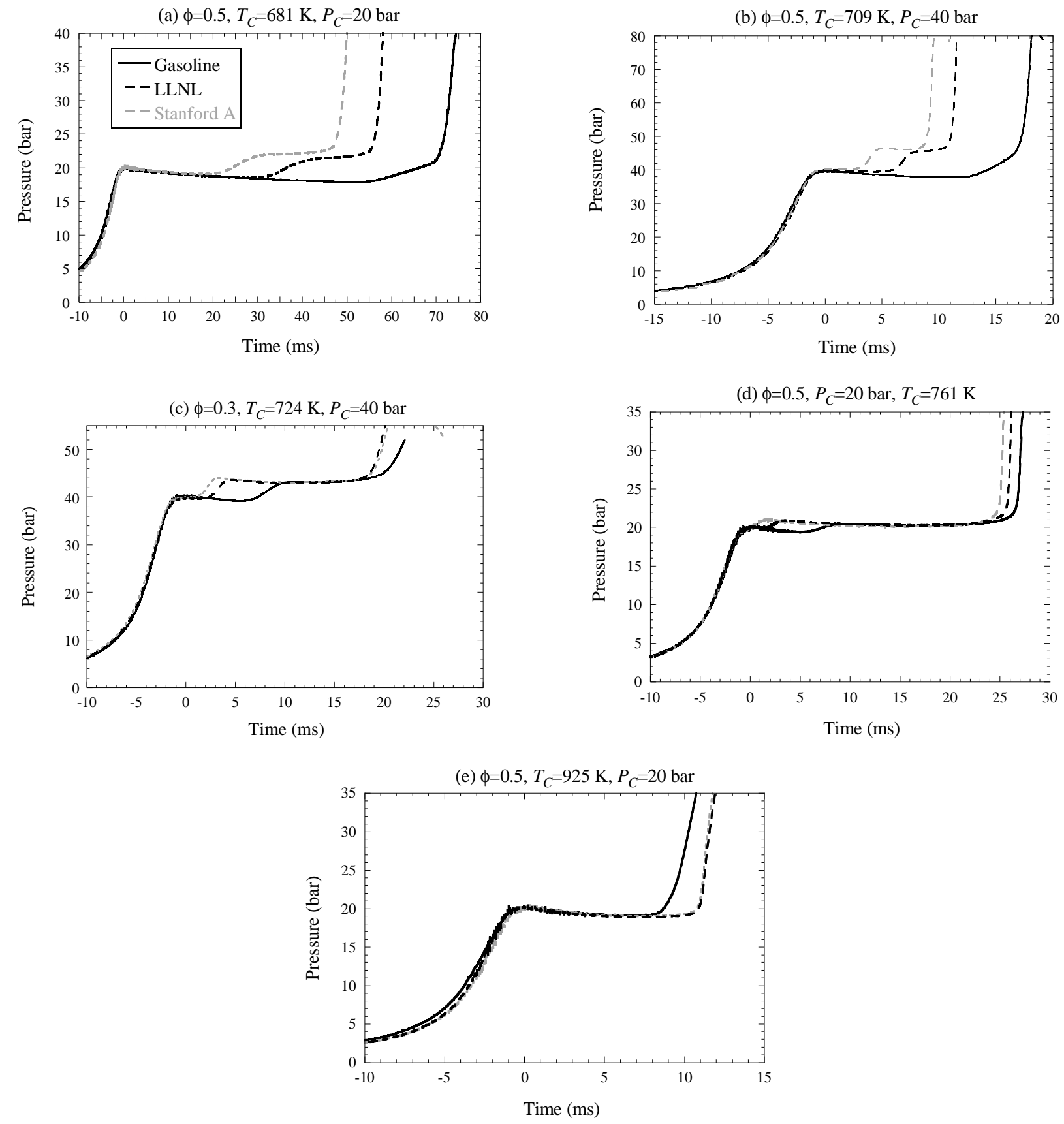

Figure 7 
(a) LLNL Surrogate, $\phi=0.5, P_{C}=20 \mathrm{bar}, T_{C}=763 \mathrm{~K}$

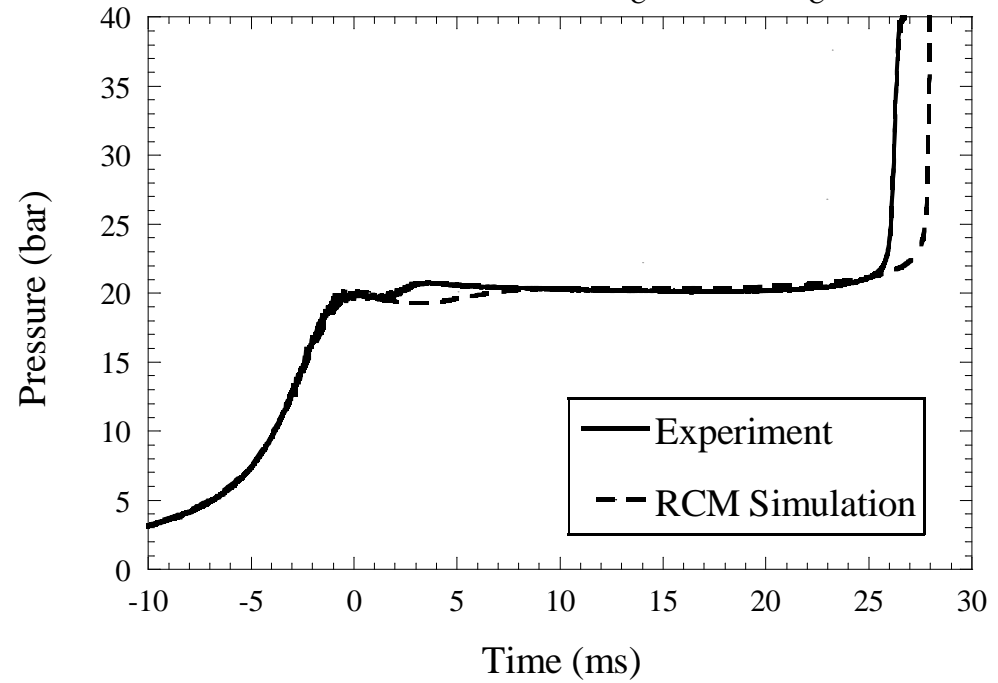

(b) Stanford A Surrogate, $\phi=0.5, P_{C}=20 \mathrm{bar}, T_{C}=731 \mathrm{~K}$

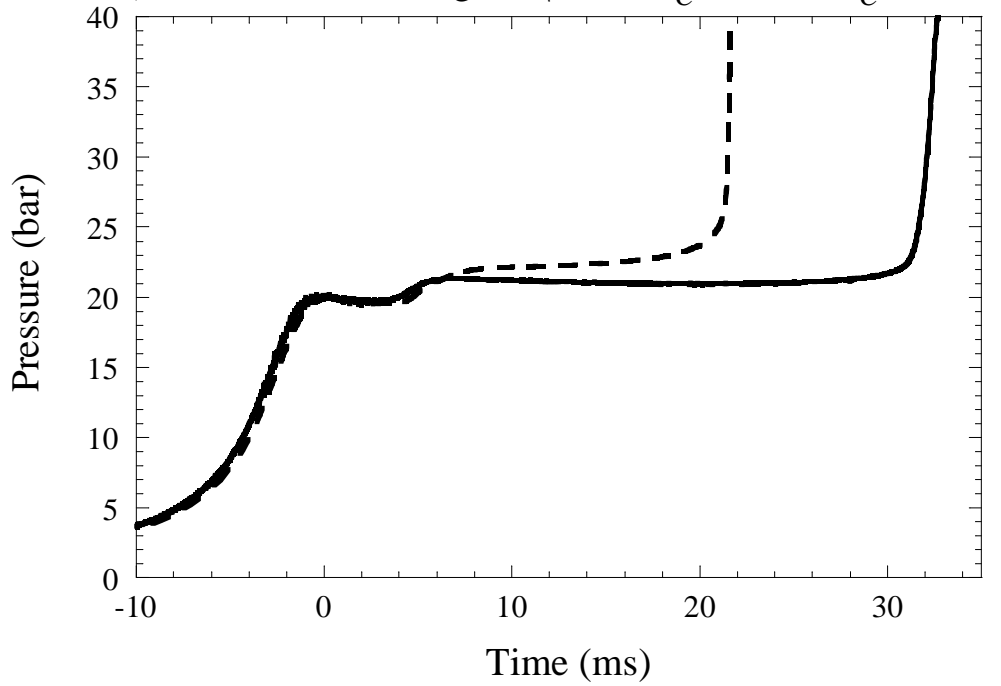

Figure 8 


$$
\phi=0.5, P_{C}=20 \mathrm{bar}
$$
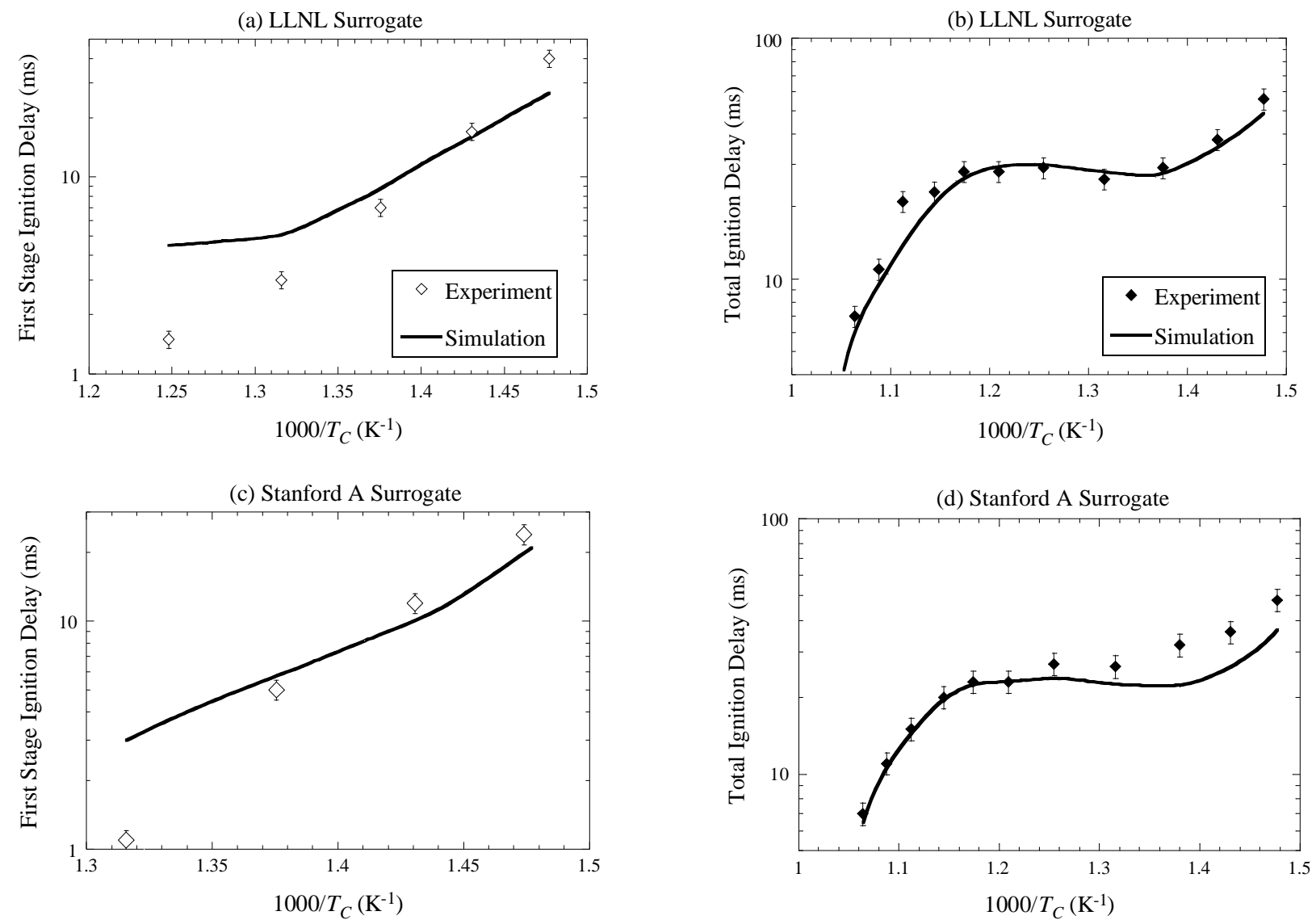

Figure 9 


\section{$P_{C}=40$ bar}

(a) LLNL Surrogate

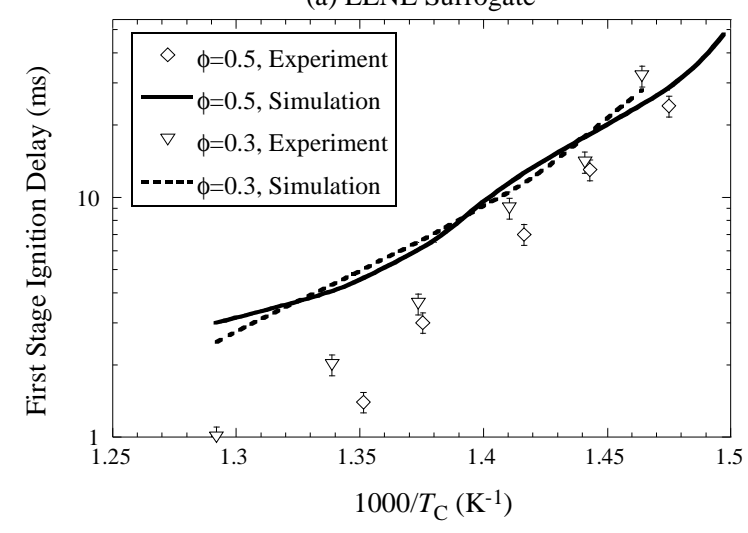

(c) Stanford A Surrogate

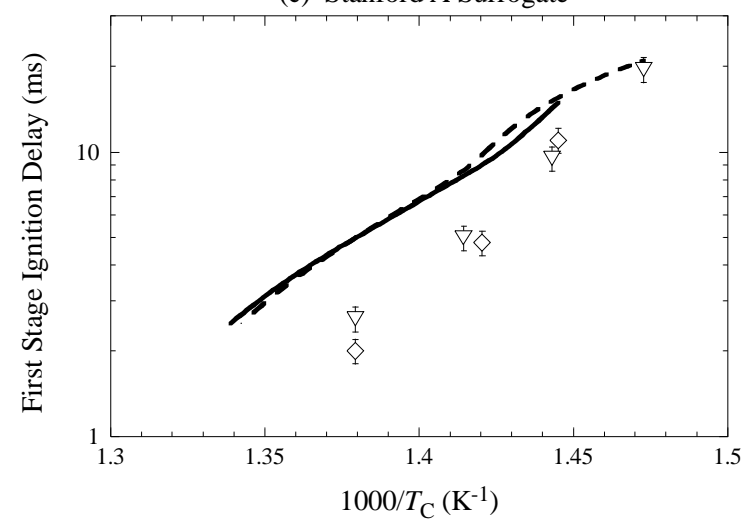

(b) LLNL Surrogate

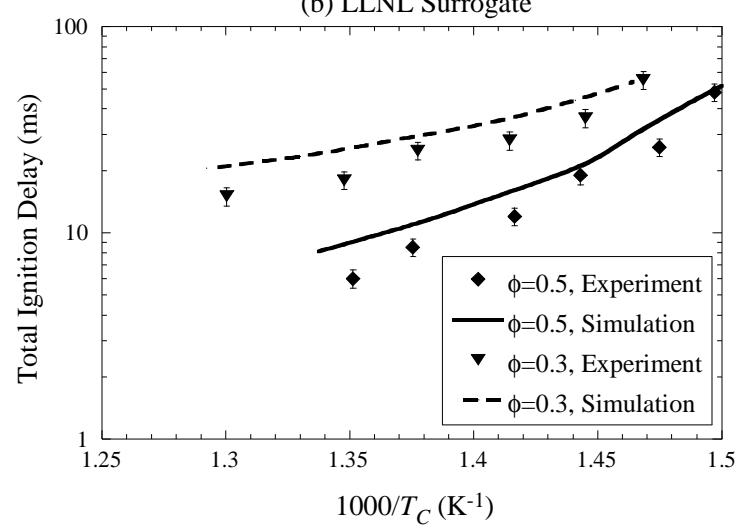

(d) Stanford A Surrogate

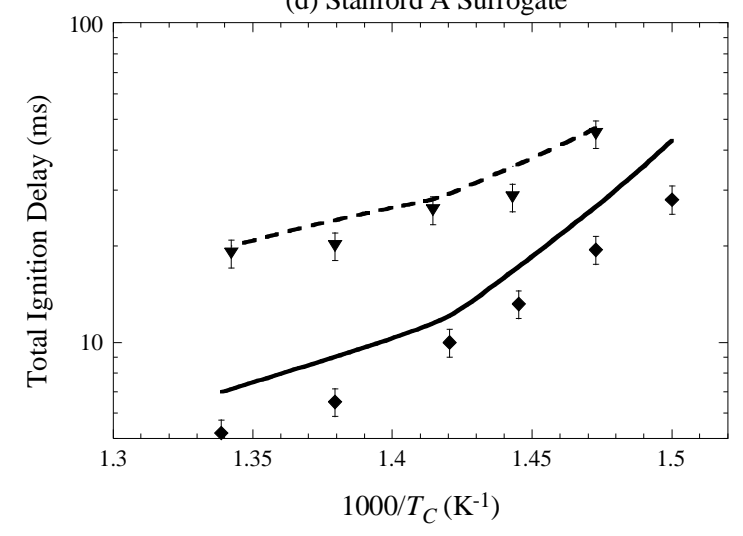

Figure 10 


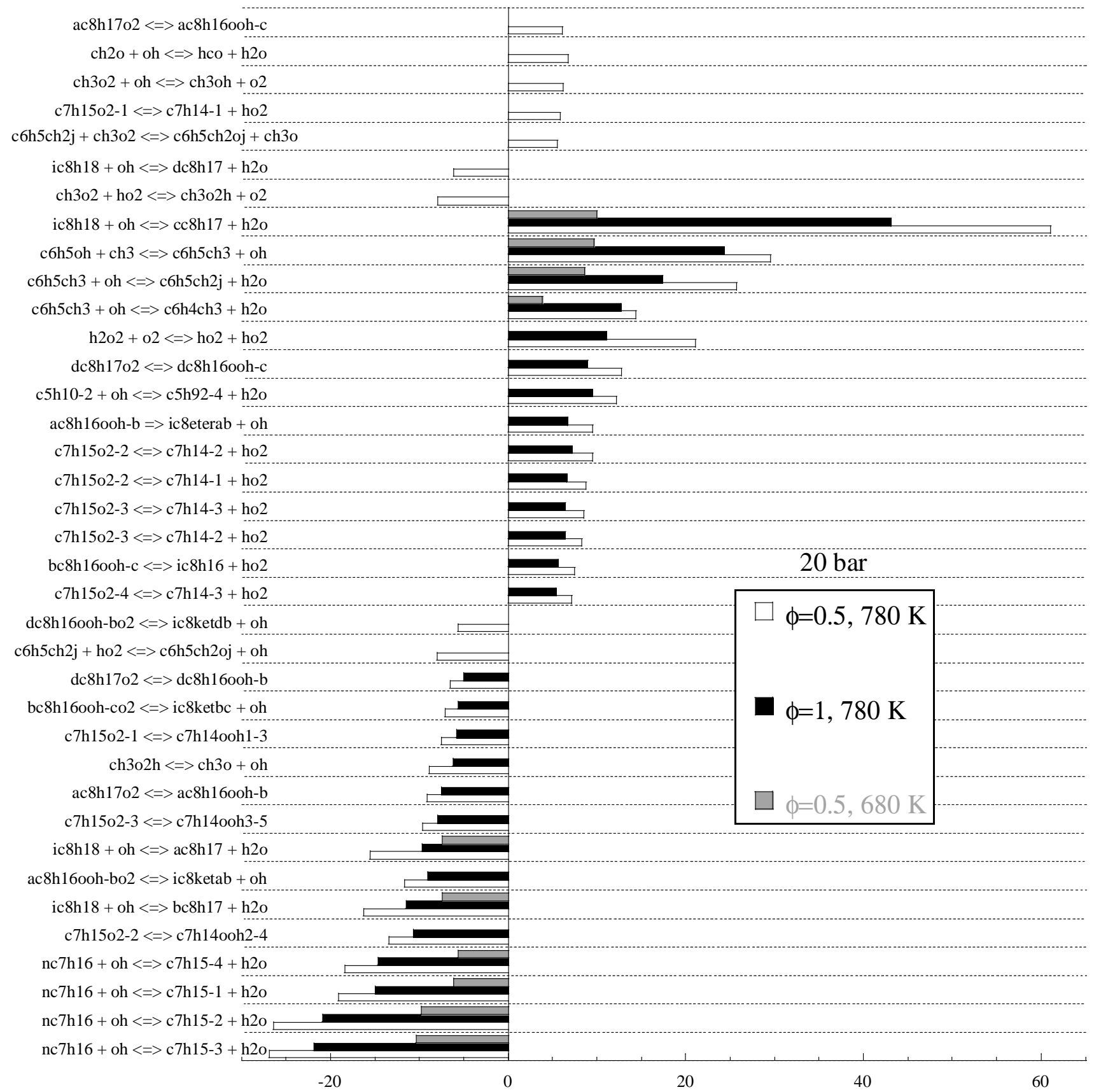

First Stage Ignition Delay Sensitivity Coefficient, $S_{\tau 1}$

\section{Figure 11}




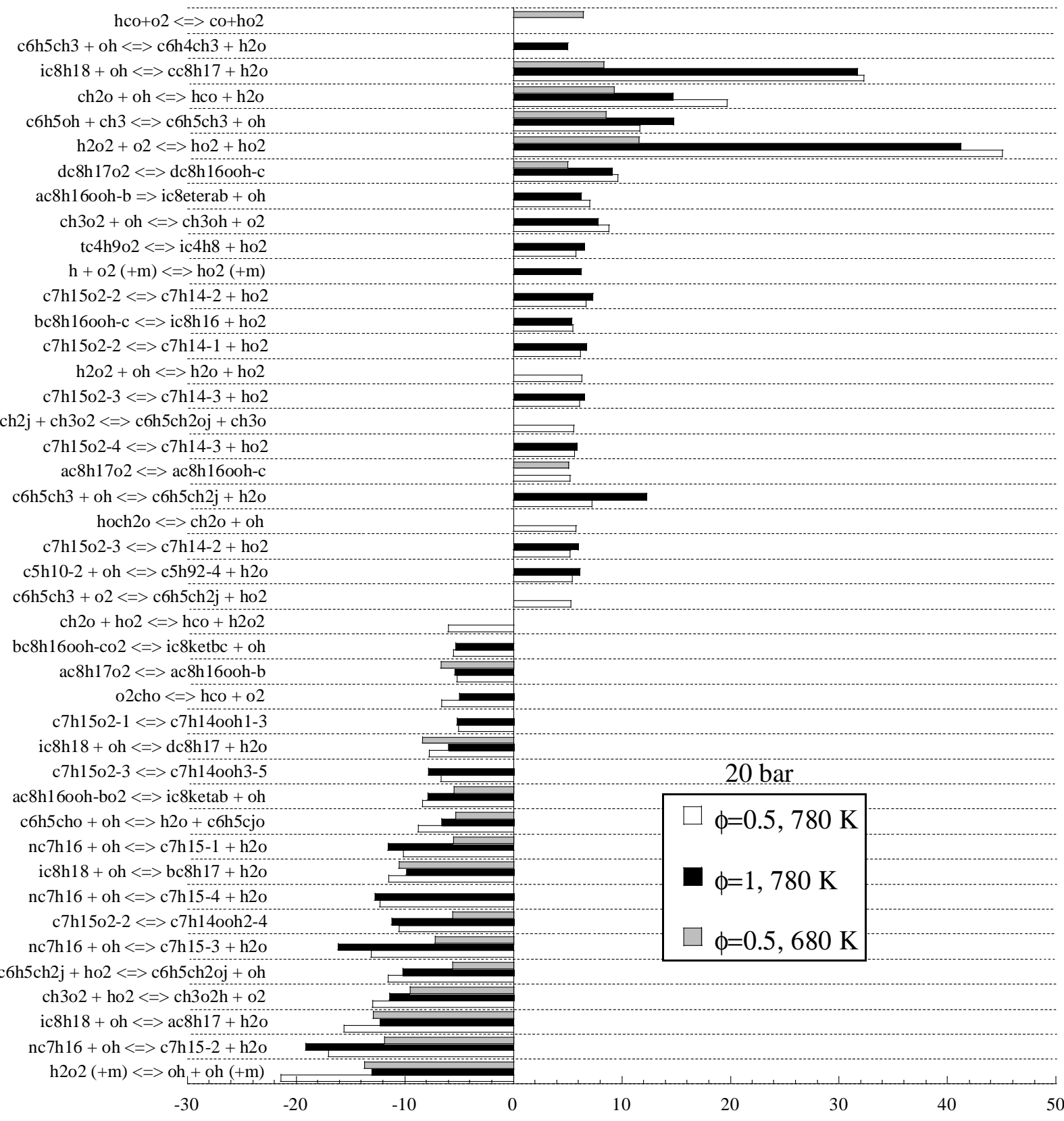

Total Ignition Delay Sensitivity Coefficient, $S_{\tau}$

Figure 12 


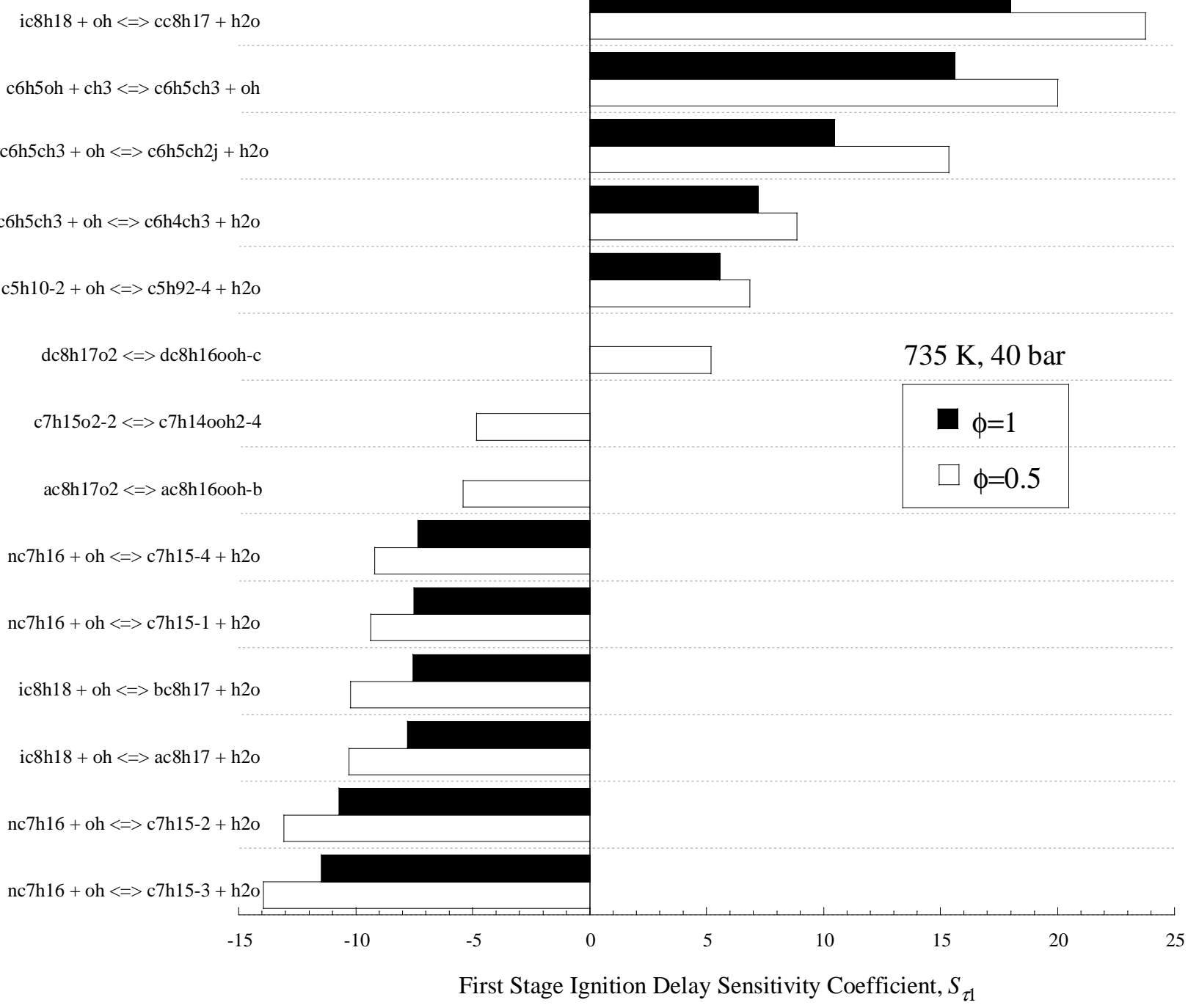

Figure 13 


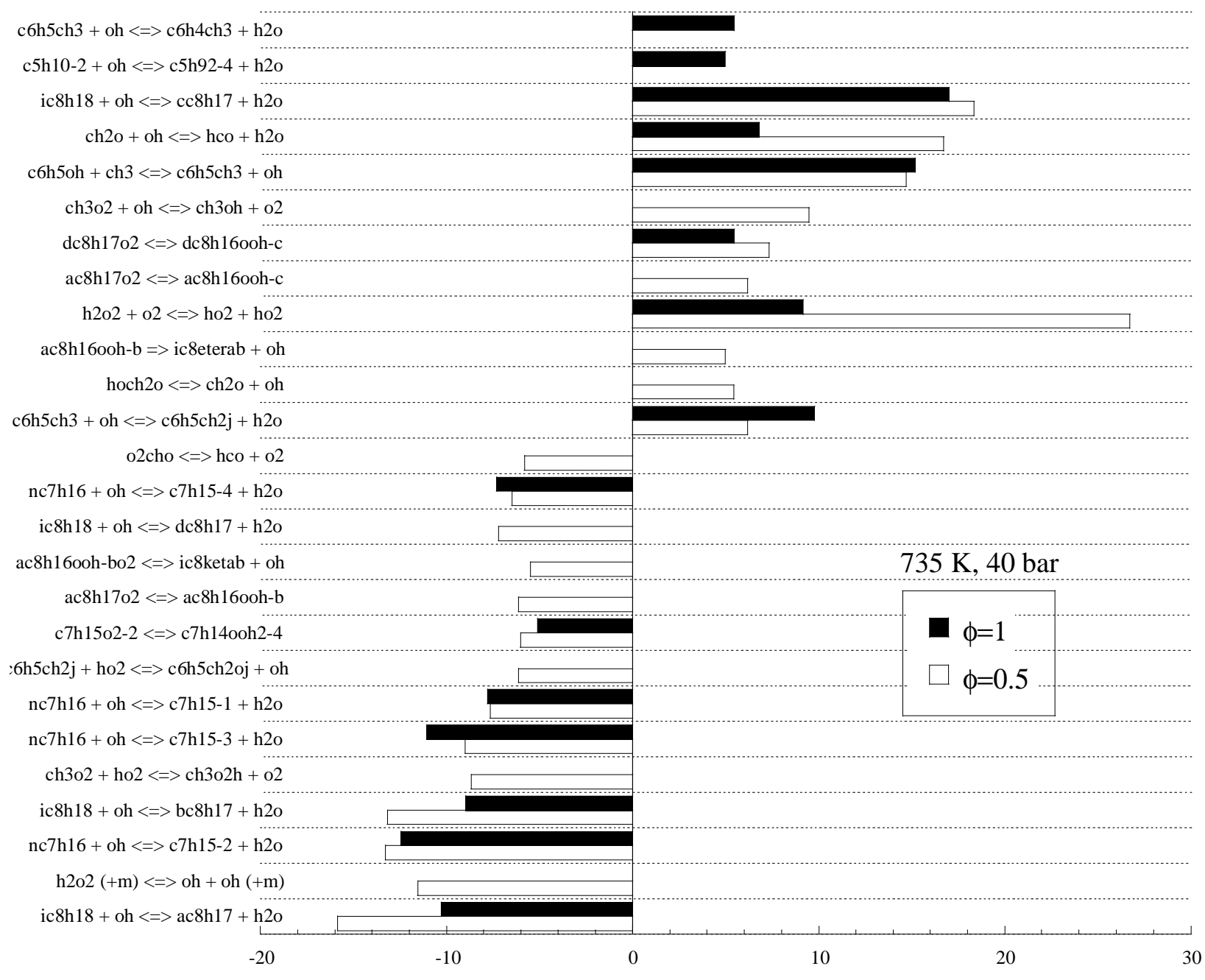

Total Ignition Delay Sensitivity Coefficient, $S_{\tau}$

Figure 14 


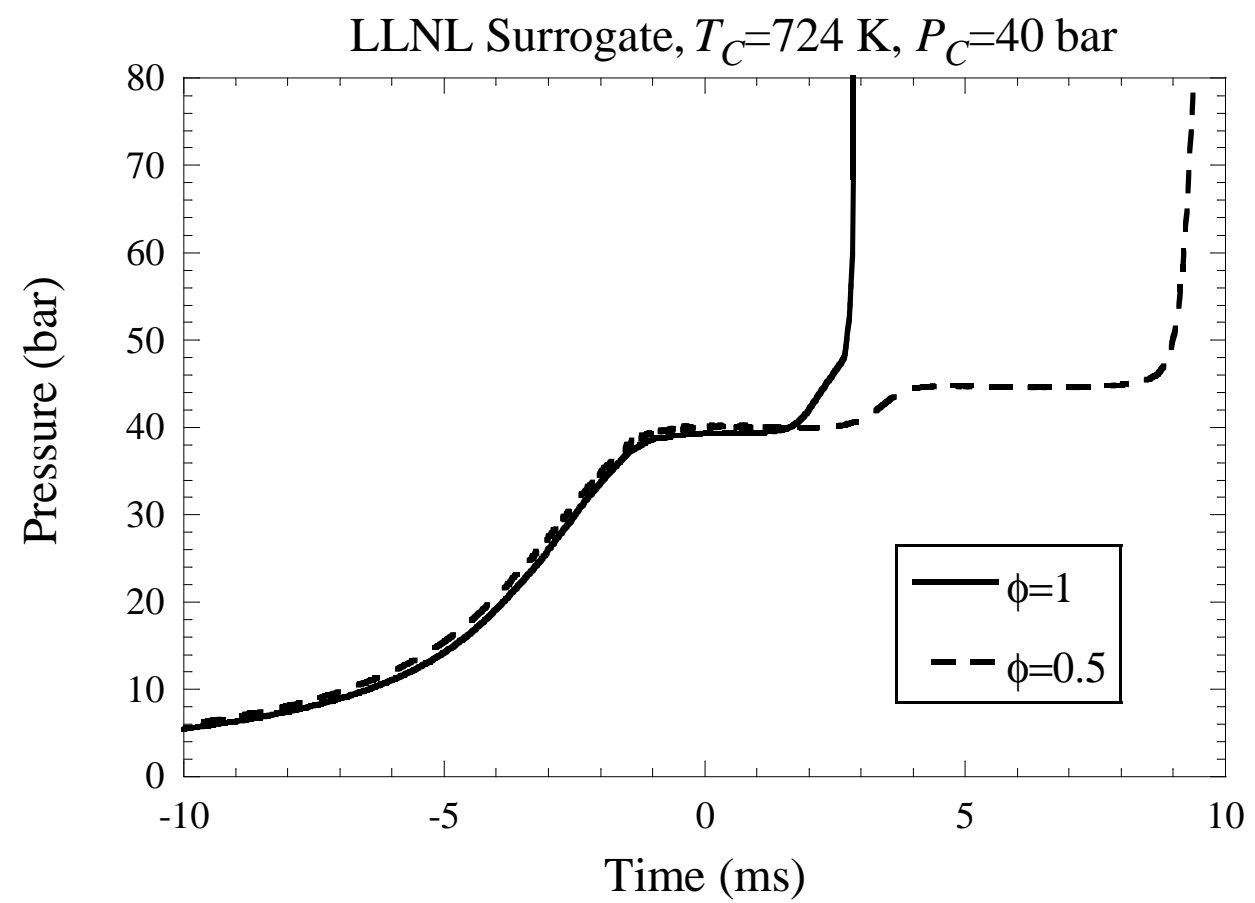

Figure 15 
Table 1

\begin{tabular}{|c|c|c|c|c|}
\hline Blend & Composition $^{\mathrm{a}}$ & AKI $^{\mathrm{b}}$ & Sensitivity $^{\mathrm{d}}$ & H/C Ratio \\
\hline RD387 Gasoline [10] & $42.3 / 9.5 / 26.4 / 4.7 / 16$ & 86.8 & 8.3 & 1.87 \\
\hline Mehl et al. [6] & $57 / 16 / 23 / 4 / 0$ & $87^{\mathrm{c}}$ & $8^{\mathrm{c}}$ & 1.94 \\
\hline Gauthier et al. [4] & $63 / 17 / 20 / 0 / 0$ & $86.5^{\mathrm{c}}$ & $5^{\mathrm{c}}$ & 1.97 \\
\hline
\end{tabular}

a Composition order: iso-Alkanes/n-Alkanes/Aromatics/Olefins/Napthenes (volume fraction in liquid phase at $25^{\circ} \mathrm{C}$ ).

b Anti-Knock Index $(\mathrm{AKI})=(\mathrm{RON}+\mathrm{MON}) / 2$.

c The values are estimated using the correlations proposed in Mehl et al. [6].

d $\quad$ Sensitivity $=$ RON-MON.

Table 2

\begin{tabular}{|c|c|c|c|c|}
\hline$\phi$ & $P_{C}(\mathrm{bar})$ & $T_{0}\left({ }^{\circ} \mathrm{C}\right)$ & RD387 Gasoline & Surrogates \\
\hline \hline 0.3 & 40 & 60 & {$[10]$} & This Study \\
\hline 0.5 & 20 & 90,125 & {$[10]$} & This Study \\
\hline 0.5 & 40 & 60 & {$[10]$} & This Study \\
\hline 1 & 20 & 60,90 & {$[10]$} & {$[16]$} \\
\hline 1 & 40 & 60 & {$[10]$} & {$[16]$} \\
\hline
\end{tabular}


Table 3

\begin{tabular}{|cccccc|cccccc||}
\hline \multicolumn{7}{|c|}{ LLNL Surrogate } & \multicolumn{7}{c|}{ Stanford A Surrogate } \\
\hline$\phi$ & $\begin{array}{c}P_{C} \\
(\mathrm{bar})\end{array}$ & $\begin{array}{c}T_{C} \\
(\mathrm{~K})\end{array}$ & $\begin{array}{c}1000 / T_{C} \\
(1 / \mathrm{K})\end{array}$ & $\begin{array}{c}\tau \\
(\mathrm{ms})\end{array}$ & $\begin{array}{c}\tau_{1} \\
(\mathrm{~ms})\end{array}$ & $\phi$ & $\begin{array}{c}P_{C} \\
(\mathrm{bar})\end{array}$ & $\begin{array}{c}T_{C} \\
(\mathrm{~K})\end{array}$ & $\begin{array}{c}1000 / T_{C} \\
(1 / \mathrm{K})\end{array}$ & $\begin{array}{c}\tau \\
(\mathrm{ms})\end{array}$ & $\begin{array}{c}\tau_{1} \\
(\mathrm{~ms})\end{array}$ \\
\hline 0.5 & 20 & 681 & 1.468 & 56 & 40 & 0.5 & 20 & 681 & 1.468 & 48 & 24 \\
0.5 & 20 & 699 & 1.431 & 38 & 17 & 0.5 & 20 & 699 & 1.431 & 36 & 12 \\
0.5 & 20 & 731 & 1.368 & 29 & 7 & 0.5 & 20 & 731 & 1.368 & 34 & 5 \\
0.5 & 20 & 761 & 1.314 & 26 & 3 & 0.5 & 20 & 761 & 1.314 & 26 & 1.1 \\
0.5 & 20 & 803 & 1.245 & 29 & - & 0.5 & 20 & 803 & 1.245 & 27 & - \\
0.5 & 20 & 831 & 1.203 & 28 & - & 0.5 & 20 & 831 & 1.203 & 23 & - \\
0.5 & 20 & 858 & 1.166 & 28 & - & 0.5 & 20 & 858 & 1.166 & 23 & - \\
0.5 & 20 & 882 & 1.134 & 23 & - & 0.5 & 20 & 882 & 1.134 & 20 & - \\
0.5 & 20 & 898 & 1.114 & 21 & - & 0.5 & 20 & 898 & 1.114 & 15 & - \\
0.5 & 20 & 925 & 1.081 & 11 & - & 0.5 & 20 & 925 & 1.081 & 11 & - \\
0.5 & 20 & 950 & 1.053 & 7 & - & 0.5 & 20 & 950 & 1.053 & 7 & - \\
0.5 & 40 & 668 & 1.497 & 48 & - & 0.5 & 40 & 666 & 1.497 & 27 & 25 \\
0.5 & 40 & 678 & 1.474 & 26 & 24 & 0.5 & 40 & 679 & 1.474 & 19 & 15 \\
0.5 & 40 & 692 & 1.443 & 19 & 13 & 0.5 & 40 & 692 & 1.443 & 12 & 9 \\
0.5 & 40 & 709 & 1.416 & 12 & 7 & 0.5 & 40 & 705 & 1.416 & 9.5 & 4 \\
0.5 & 40 & 727 & 1.375 & 8.5 & 3 & 0.5 & 40 & 724 & 1.375 & 6.5 & 2 \\
0.5 & 40 & 748 & 1.351 & 6 & 1.4 & 0.3 & 40 & 679 & 1.464 & 44 & 20 \\
0.3 & 40 & 683 & 1.468 & 55 & 32 & 0.3 & 40 & 693 & 1.440 & 28 & 9 \\
0.3 & 40 & 694 & 1.445 & 36 & 14 & 0.3 & 40 & 708 & 1.410 & 24 & 5 \\
0.3 & 40 & 709 & 1.414 & 28 & 9 & 0.3 & 40 & 725 & 1.373 & 16 & 2 \\
0.3 & 40 & 724 & 1.377 & 25 & 3.6 & 0.3 & 40 & 744 & 1.338 & 15 & 1.5 \\
0.3 & 40 & 747 & 1.347 & 18 & 2 & & & & & & \\
\hline
\end{tabular}


Table 4

\begin{tabular}{|c|c|}
\hline & \\
\hline
\end{tabular}

